UNIVERSIDADE ESTADUAL PAULISTA

FACULDADE DE MEDICINA VETERINÁRIA E ZOOTECNIA

SEQUENCIAMENTO DO RNAm CODIFICANTE DA HEPCIDINA E ANÁLISE DE SUA EXPRESSÃO GÊNICA EM DIFERENTES TECIDOS DE OVINOS SAUDÁVEIS

PERES RAMOS BADIAL

Botucatu - SP

Fevereiro de 2010 
UNIVERSIDADE ESTADUAL PAULISTA

FACULDADE DE MEDICINA VETERINÁRIA E ZOOTECNIA

\section{SEQUENCIAMENTO DO RNAm CODIFICANTE DA HEPCIDINA E ANÁLISE DE SUA EXPRESSÃO GÊNICA EM DIFERENTES TECIDOS DE OVINOS SAUDÁVEIS}

PERES RAMOS BADIAL

Dissertação apresentada junto ao Programa de Pós-Graduação em Medicina Veterinária para a obtenção do título de mestre.

Orientador: Prof. Dr. Alexandre Secorun Borges Co-orientador: Prof. Dr. Paulo Eduardo Martins Ribolla

Botucatu - SP

Fevereiro de 2010 
FICHA CATALOGRÁFICA ELABORADA PELA SEÇÃO TÉC. AQUIS. E TRAT. DA INFORMAÇÃO DIVISÃO TÉCNICA DE BIBLIOTECA E DOCUMENTAÇÃO - CAMPUS DE BOTUCATU - UNESP BIBLIOTECÁRIA RESPONSÁVEL: ROSEMEIRE APARECIDA VICENTE

Badial, Peres Ramos.

Sequenciamento do RNAm codificante da Hepcidina e análise de sua expressão gênica em diferentes tecidos de ovinos saudáveis/ Peres Ramos Badial. - Botucatu: [s.n.], 2010

Dissertação (mestrado) - Faculdade de Medicina Veterinária e Zootecnia, Universidade Estadual Paulista, 2010.

Orientador: Prof. Dr. Alexandre Secorun Borges

Co-orientador: Prof. Dr. Paulo Eduardo Martins Ribolla

Assunto CAPES: 50500007

1. Ovinos. 2. Hepcidina. 3. Expressão gênica.

Palavras chave: Hepcidina; Imunidade inata; Ovinos; Expressão de RNA mensageiro; Peptídeo antimicrobiano. 
Nome do autor: Peres Ramos Badial

Título: SEQUENCIAMENTO DO RNAm CODIFICANTE DA HEPCIDINA E ANÁLISE DE SUA EXPRESSÃO GÊNICA EM DIFERENTES TECIDOS DE OVINOS SAUDÁVEIS

\section{COMISSÃO EXAMINADORA}

Prof. Dr. Alexandre Secorun Borges

Presidente e Orientador

Departamento de Clínica Veterinária

FMVZ - UNESP - Botucatu

Prof. Dr. João Pessoa Araújo Júnior

Membro

Departamento de Microbiologia e Imunologia

Instituto de Biociências de Botucatu

Prof. Dra. Juliana Regina Peiró

Membro

Departamento de Clínica e Cirurgia e Reprodução Animal

Faculdade de Odontologia de Araçatuba

Data da defesa: 18 de fevereiro de 2010. 
À minha mãe, VALIANA FAUTH RAMOS, pelo amor, apoio, incentivo, dedicação, fé e força.

À minha irmã, PÉRSIDE RAMOS BADIAL, pelo amor, apoio, paciência e dedicação. 


\section{AGRADECIMENTOS}

A DEUS que permitiu minha existência e que até hoje guiou meus caminhos.

Ao Prof. Alexandre Secorun Borges pela orientação, pela amizade, pelo incentivo, pela confiança, pelos ensinamentos e pelas horas de conversa. Agradecimentos também a sua esposa Alessandra Gonçalves Borges.

A minha namorada Luisa Gouvêa Teixeira pelo apoio e incentivo.

Ao Prof. Paulo Eduardo Martins Ribolla pela co-orientação e auxílio na realização deste trabalho. Agradecimentos também a sua esposa Débora Colombi.

Aos pós-graduandos e amigos, Paulo Henrique Jorge da Cunha, José Paes de Oliveira Filho, Andreza Pimenta de Oliveira e Didier Quevedo Cagnini, pela amizade e pelo convívio nos últimos anos, sem os quais este trabalho não estaria concluído.

À professora Renée Laufer-Amorim pela amizade e pelos mais de cinco minutos que fizeram a diferença.

Ao Prof. João Pessoa Araújo Júnior pela atenção e disponibilidade dispensadas.

Aos amigos de República Luis Emiliano Cisneros Álvarez e Aruaque Lotufo Ferraz de Oliveira pela convivência extremamente agradável.

Aos amigos de pós-graduação Fábio André Pinheiro de Araújo, Guilherme Augusto Marietto Gonçalves, Flávia Augusta de Oliveira, Ivan Felismino Charas dos Santos e Nicole Ruas de Sousa por compartilharem suas vidas comigo.

Às acadêmicas da graduação e bolsistas PIBIC, Ana Claudia Gorino e Mariana Fontanetti Marinheiro pelo auxílio e dedicação ao projeto.

À bióloga e bolsista de treinamento Técnico da FAPESP, Jésica Ruiz Silva pelo auxílio no desenvolvimento das atividades do projeto, no Laboratório de Biologia Molecular da Clínica Veterinária da FMVZ/UNESP.

Aos docentes do Serviço de Clínica de Grandes Animais da FMVZ, Prof. Roberto Calderon Gonçalves, Prof. Rogério Martins Amorin e Prof. Simone Biagio Chiacchio, pela recepção e cooperação na realização deste trabalho. 
Às pós-graduandas, do Laboratório de Diagnóstico Molecular do Instituto Biológico de Botucatu, Andreza Soriano Figueiredo e Taís Fukuta da Cruz pela disponibilidade e colaboração.

Às secretárias do Departamento de Clínica Veterinária, Marlene Dias de Camargo e Izabel Cristina Castro, pela disponibilidade e colaboração.

Aos Médicos Veterinários Residentes e funcionários da Clínica de Grandes Animais da FMVZ/UNESP/ Botucatu pela amizade e ajuda na realização deste trabalho.

Às docentes do Departamento de Genética do Instituto Biológico de Botucatu Ligia Souza Lima Silveira da Mota e Adriane Pinto Wasko e as pósgraduandas Ana Teresa Burlamaqui Faraco Antonangelo e Magali Lira Gomes pela disponibilidade, colaboração e ajuda na realização deste trabalho.

Ao Programa de Pós-Graduação em Medicina Veterinária, especialmente à Professora Sheila Canevese Rahal (Coordenadora) e aos funcionários José Roberto de Lalla Júnior (Supervisor) e Maria Ap. Dias de Almeida Manoel, pelo auxílio e orientações com relação às questões burocráticas da pós-graduação.

A CAPES, pela concessão da Bolsa de Demanda Social.

Ao CNPq, pelo auxílio financeiro concedido para a realização deste trabalho.

Aos animais, instrumentos de aprendizado e razão principal para o desenvolvimento da pesquisa. 


\section{LISTA DE TABELAS}

CAPÍTULO II

Table 1 Nucleotide sequences of primers used for specific gene 44 amplification and for quantitative real-time PCR studies of sheep hepcidin.

Table 2 Relative expression of basal sheep hepcidin mRNA in different 45 tissues from four healthy sheep. 


\section{LISTA DE FIGURAS \\ CAPÍTULO II}

Figure 1 (A) Open reading frame (top) and deduced amino acid (bottom)

sequences of sheep hepcidin. Start and stop codons are in italics. Splice sites for introns 1 and 2 are indicated with arrows. (B) Amino acid sequence of the sheep signal peptide, pro-region and mature hepcidin. Underlined residues indicate the predicted furin cleavage site.

Figure 2 Phylogenic tree showing the relationship of the sheep hepcidin amino acid sequence with previously identified hepcidin sequences. The phylogeny was constructed using the Clustal $\mathrm{X}$ program, and the evolutionary history was inferred using the Neighbor-Joining method. The numbers next to the branches show bootstrap majority consensus values on 1000 replicates in percent (Felsenstein, 1985). All positions containing gaps and missing data were eliminated from the dataset. Phylogenetic analyses were conducted in MEGA4.

Figure 3 Species comparison of hepcidin amino acid sequence. 48 Percentages of identity of each sequence relative to sheep follows each sequence. The sequence alignment was constructed using the Clustal X program. GenBankTM accession numbers: Homo sapiens, NP_066998.1; Bubalus bubalis, ABY81280.2; Bos taurus, NP_001107980.1; Sus scrofa, NP_999282.1; Canis lupus familiaris, NP_001007141.1; Equus caballus, GQ_253624; Rattus norvegicus, NP_445921.1 and Mus musculus, NP_115930.1. 
Figure 4 Species comparison of the mature hepcidin amino acid sequence. 49 Percentages of identity of each sequence relative to sheep follows each sequence. The sequence alignment was constructed using the Clustal X program. Underlined residues indicate essential amino acid sequences for binding to ferroportin. Eight conserved cysteine $(\mathrm{C})$ residues in the mature hepcidin are indicated in gray. 


\section{LISTA DE TABELAS}

ANEXOS

Tabela 1 Valores individuais, médias, desvios-padrão (DP) e i medianas dos CT's das duplicatas de hepcidina (1) e $\beta$-actina (2) ovina, obtidos pelo programa de detecção (Applied Bioystems, model 7300, versão 1.2.3), das amostras dos diferentes lobos do fígado.

Tabela 2 Valores individuais, médias, desvios-padrão (DP) e ii medianas dos CT's das duplicatas de hepcidina (1) e $\beta$-actina (2) ovina, obtidos pelo programa de detecção (Applied Bioystems, model 7300, versão 1.2.3), das amostras de abomaso, intestino, pulmão, coração, bexiga e linfonodo.

Tabela 3 Valores individuais, médias, desvios-padrão (DP) e iii medianas dos CT's das duplicatas de hepcidina (1) e $\beta$-actina (2) ovina, obtidos pelo programa de detecção (Applied Bioystems, model 7300, versão 1.2.3), das amostras de rim, músculo, baço, cerebelo, medula óssea e córtex encefálico. 


\section{LISTA DE ABREVIAÇÕES}

HAMP - Hepcidin antimicobrial peptide

LEAP-1 - Peptídeo antimicrobiano expresso no fígado

Hepc - Hepcidina

FPN - Ferroportina

ERO - Espécies reativas de oxigênio

SRE - Sistema reticuloendotelial

DCytb - Citocromo-b duodeno ferro redutase

DMT1 - Proteína transportadora de metais divalentes

Heph - Hefaestina

TFR1 - Receptor de transferrina - 1

LPS - Lipopolissacarídeo

PHD - Prolil-hidroxilase

VHL - Proteína supressora do tumor de Von Hippel-Lindau

EPO - Eritropoetina

GDF15 - Fator de diferenciação do crescimento-15

$\mathrm{HH}$ - Hemocromatose hereditária

$ß_{2} \mathrm{M}-ß_{2}$ Microglobulina

TFR2 - Receptor de transferrina - 2

HJV - Hemojuvelina

GPI - Glicosilfosfatidilinositol

HJVs - Hemojuvelina solúvel

BMPR - Receptor da BMP

* Em virtude do uso consagrado na literatura técnica, algumas abreviações não estão inclusas nesta lista, além disso, outras seguem sua grafia em inglês. 


\section{SUMÁRIO}

Página

\section{CAPÍTULO I}

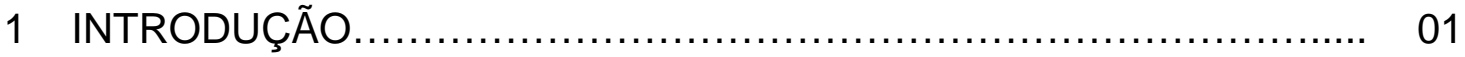

2 REVISÃO DE LITERATURA ................................................ 06

2.1 Aspectos gerais sobre a Hepcidina..................................... 06

2.2 Alvo molecular da Hepcidina............................................... 07

2.3 Metabolismo do ferro........................................................... 08

2.4 Mecanismos de ação............................................................... 10

2.4.1 Atividade regulatória sobre o ferro.............................. 10

2.4 .2 Atividade antimicrobiana........................................... 11

2.5 Fatores responsáveis pela regulação da expressão de 12 Hepcidina ................................................................... 12

2.5.1 Estimuladores da síntese de Hepcidina......................... 12

2.5.2 Inibidores da síntese de Hepcidina................................ 14

2.6 Principais vias envolvidas na regulação da expressão de Hepcidina.

2.6.1 HFE e Hepcidina.

2.6.2 TFR2 e Hepcidina............................................... 17

2.6.3 Hemojuvelina e Hepcidina..................................... 18

2.6.4 Inflamação e Hepcidina........................................... 19

2.6.5 Hipóxia e Hepcidina............................................. 20

CAPÍTULO II - Trabalho científico................................................... 21

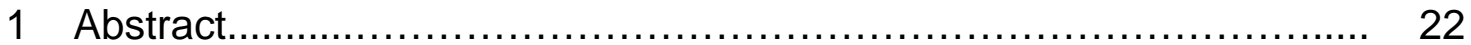

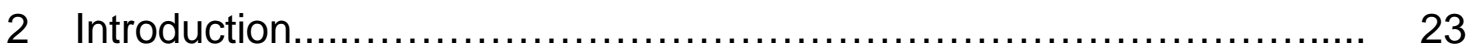

3 Material and methods................................................. 25

3.1 Animals................................................................ 25

3.2 RNA isolation, RT-PCR and sequence analysis...................... 26

3.3 Expression analysis of sheep hepcidin by real-time PCR ......... 28

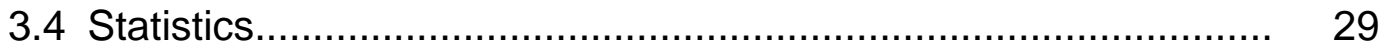

3.5 Accession numbers....................................................... 29

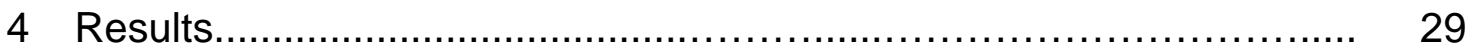

4.1 Identification and characterization of sheep hepcidin cDNA...... 29

4.2 Expression analysis of sheep hepcidin by RT-PCR ............ 31

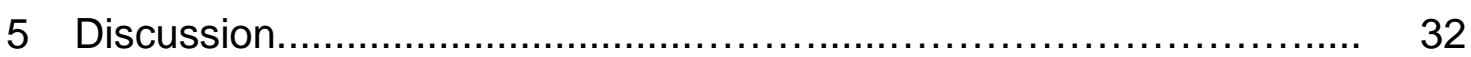




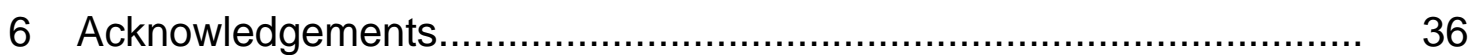

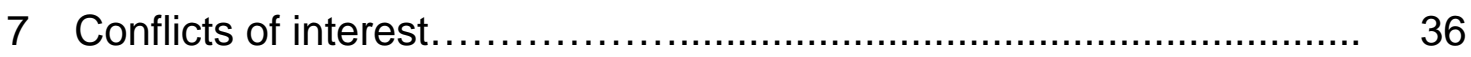

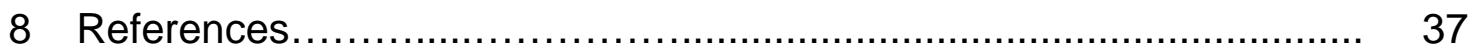

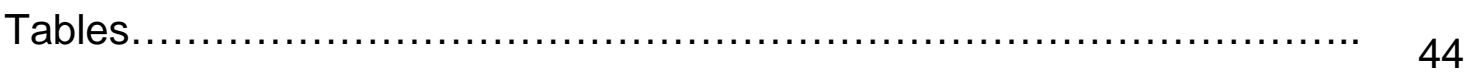

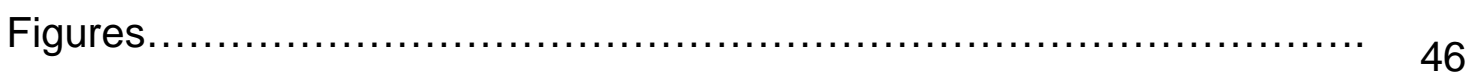

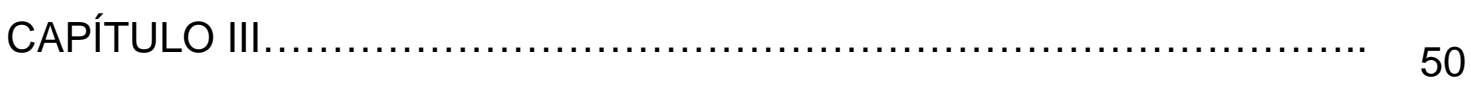

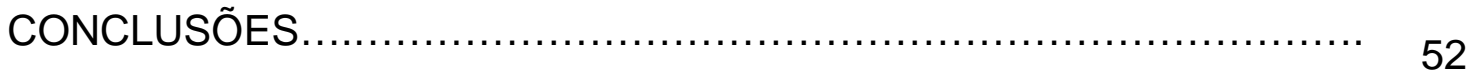

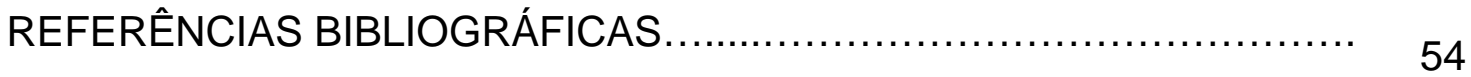

ANEXOS 
BADIAL, P.R. Sequenciamento do RNAm codificante da Hepcidina e análise de sua expressão gênica em diferentes tecidos de ovinos saudáveis. Botucatu, 2010. 66 p. Dissertação (Mestrado) - Faculdade de Medicina Veterinária e Zootecnia, Campus de Botucatu, Universidade Estadual Paulista.

\section{RESUMO}

A hepcidina é uma proteína que faz parte do sistema imune inato e desempenha um papel fundamental na regulação da homeostase do ferro. Este peptídeo foi previamente caracterizado em várias espécies, entretanto, até agora, não em ovinos. O objetivo deste estudo foi de determinar a sequência do RNAm codificante da hepcidina, bem como caracterizar e realizar a análise da expressão gênica deste peptídeo em diferentes tecidos de ovinos saudáveis. A região codificante da hepcidina consiste em 249 pares de base, as quais codificam um peptídeo contendo 82 aminoácidos. Este precursor, da forma bioativa da hepcidina, apresenta maior homologia com as sequências de Bos taurus e Bubalus bubalis. A hepcidina foi expressa predominantemente no fígado dos ovinos, contudo foram observados altos níveis de expressão no abomaso e baixos níveis nos outros tecidos. Estes resultados ampliam o conhecimento comparativo deste peptídeo, mostrando a relação da hepcidina ovina com a de outras espécies de mamíferos e será útil para estudos futuros sobre o metabolismo de ferro e do processo inflamatório nos ovinos.

Palavras chave: Hepcidina, Imunidade inata, Ovinos, Expressão de RNA mensageiro, Peptídeo antimicrobiano. 
BADIAL, P.R. Sequencing of coding mRNA and analysis of Hepcidin gene expression in different healthy sheep tissues. Botucatu, 2010. 66 p. Dissertação (Mestrado) - Faculdade de Medicina Veterinária e Zootecnia, Campus de Botucatu, Universidade Estadual Paulista.

\begin{abstract}
Hepcidin is part of the innate immune system, and plays a central role in the regulation of iron homeostasis. This peptide has been previously characterized in several species but not in sheep until now. The aim of this study was to sequence, characterize and perform hepcidin gene expression analysis in different tissues of healthy sheep. The resulting ORF consisted of 249 bp predicted to encode an 82 amino acids peptide. The deduced precursor was mostly homologous to Bos taurus and Bubalus bubalis. Hepcidin was predominantly expressed in liver, although high expression was present in abomasum and lower level expression occurred in other tissues. These findings extend our comparative knowledge of this peptide, showing the relationship between sheep hepcidin and other mammalian hepcidins and might be helpful for additional studies on iron metabolism and inflammatory process in sheep.
\end{abstract}

Keywords: Hepcidin, Innate immunity, Sheep, mRNA expression, Antimicrobial peptide. 
capítulo I 
INTRODUÇÃO 


\section{INTRODUÇÃO}

A ovinocultura vem se consolidando no agronegócio brasileiro. No período de 2000 até 2005 o rebanho de ovinos do Brasil cresceu de 14,8 para 16 milhões de cabeças, representando um crescimento de $8,10 \%$. Na região Sudeste, os rebanhos de ovinos são direcionados para produtos com maior agregação de valor, destacando-se atualmente na produção de cortes especiais. O enfoque da produção ocorre de maneira diferenciada em razão da proximidade com a cidade de São Paulo, que é o maior mercado consumidor do País (Anualpec, 2006).

Entretanto, com o crescimento da ovinocultura na Região Sudeste do Brasil, tem aumentado concomitantemente a incidência de diversas enfermidades (Ortolani, 2007). A inflamação sistêmica ocorre como parte de diversas enfermidades em ovinos (Pugh, 2001).

A detecção do processo inflamatório é essencial para o estabelecimento do tratamento apropriado. O não reconhecimento precoce da inflamação sistêmica pode promover sequelas sérias e potencialmente fatais para os ovinos (Radostits et al., 2002).

A inflamação resulta no aumento da concentração plasmática de várias proteínas. Essas proteínas são liberadas no início do desenvolvimento da inflamação e são denominadas como proteínas de fase aguda. As proteínas de fase aguda podem ser utilizadas como marcadores inespecíficos de processos inflamatórios, para diferenciar entre doença crônica e aguda, monitorar a evolução no quadro clínico e determinar prognósticos (Hulten et al., 2002; Nielsen et al., 2004; Petersen et al., 2004).

Em ruminantes, as principais proteínas de fase aguda estudadas incluem o fibrinogênio, a haptoglobina, proteína ligadora de lipopolissacarídeo, a proteína C reativa, o amilóide sérico A, a glicoproteína ácida $\alpha 1$, a ceruloplasmina, a antitripsina, e a macroglobulina a2 (Jones e Alisson, 2007).

A elevação da concentração do fibrinogênio plasmático é comumente utilizada em ovinos para indicar a presença de várias enfermidades que acarretam inflamação. Embora o fibrinogênio seja considerado uma proteína de fase aguda, seus valores só aumentam 24 a 48 horas após a indução da inflamação e se mantêm elevados durante dois a três dias (Schalm et al., 1970). 
A determinação da concentração do ferro plasmático é outra metodologia que tem sido utilizada como indicador precoce de processos inflamatórios em ratos (Hershko et al., 1974), cães (Feldman et al., 1981), bovinos (Erskine e Bartlett, 1993), equinos (Borges et al., 2007) e humanos (Mattioli et al., 2002; Cunietti et al., 2004). A concentração do ferro plasmático ou sérico diminui rapidamente em resposta a inflamação nos seres vivos, sendo este teste um indicador confiável da presença do processo inflamatório em humanos e animais (Feldman et al., 1981; Cunietti et al., 2004; Kemna et al., 2005; Jones e Alisson, 2007).

A observação das alterações no metabolismo do ferro durante a inflamação em ratos sugere que existe uma rápida diminuição da absorção intestinal e da liberação do ferro pelas células do sistema reticuloendotelial, sendo estas as principais causas da hipoferremia (Hershko et al., 1974).

Durante muito tempo os mecanismos bioquímicos e moleculares responsáveis pela menor absorção de ferro pelos enterócitos e o acúmulo de ferro dentro dos macrófagos não eram conhecidos, sendo que também não havia uma explicação convincente para a anemia presente em pacientes portadores de processos inflamatórios crônicos (Ganz e Nemeth, 2006).

O conhecimento sobre o metabolismo do ferro tem avançado radicalmente nas últimas décadas. Estudos em genética, bioquímica e biologia molecular permitiram identificar e caracterizar muitas moléculas envolvidas na regulação deste elemento.

Avanço considerável foi feito após a descoberta de um pequeno peptídeo com 25 aminoácidos denominado hepcidina, fundamental para o metabolismo do ferro. Somente após a identificação da hepcidina, o mecanismo molecular envolvido no metabolismo do ferro tornou-se esclarecido (Leong e Lönnerdal, 2004). Sua descoberta forneceu a ligação direta entre a regulação do metabolismo do ferro, a inflamação e a defesa do hospedeiro (Ganz, 2005).

A hepcidina interage diretamente com a ferroportina, a qual é expressa em enterócitos, macrófagos e hepatócitos (Nemeth et al., 2004b). A interação entre hepcidina e ferroportina permite a resposta adaptativa do organismo frente às situações que alteram a homeostase do ferro (Viatte e Vaulont, 2009). 
A hipoferremia induzida pela hepcidina durante a inflamação restringe a disponibilidade de ferro, necessária para o crescimento de microorganismos invasores. O aumento da expressão da hepcidina pode ser particularmente útil nos estágios iniciais da inflamação, antes da total mobilização dos demais componentes da imunidade inata e adaptativa (Nemeth et al., 2003). Portanto, a hepcidina é o principal regulador do ferro, o mediador chave da anemia da inflamação e a ponte entre imunidade inata e o metabolismo do ferro (Ganz, 2003; Vyoral e Petrák, 2005).

A regulação da expressão gênica da hepcidina é um processo complexo, que necessita de uma série de proteínas de membrana e diferentes vias sinalizadoras. O conhecimento mais detalhado destas proteínas e vias sinalizadoras ocorreu, com a descoberta de que proteínas envolvidas na hemocromatose hereditária humana poderiam modular a expressão da hepcidina (Anderson et al., 2007). Aproximadamente 1000 trabalhos já foram publicados após a descoberta deste peptídeo, evidenciando assim a importância deste na compreensão do metabolismo do ferro.

O sequenciamento, caracterização e análise da expressão da hepcidina já foram realizados em humanos (Krause et al., 2000; Park et al., 2001), roedores (Pigeon et al., 2001; Ilyin et al., 2003), peixes (Douglas et al., 2003; Shike et al., 2004; Zhang et al., 2004; Chen et al., 2005; Lauth et al., 2005; Wang et al., 2009), caninos (Fry et al., 2004), equinos (Oliveira Filho et al., 2009), suínos (Sang et al., 2006), pombos (Fu et al., 2007), bovinos, gatos (Hilton and Lambert, 2008), primatas não humanos (Segat et al., 2008) e bubalinos, contudo, o gene codificador da hepcidina em ovinos ainda não foi sequenciado e caracterizado e não se sabe qual o padrão de expressão deste peptídeo nos diferentes tecidos desta espécie.

O objetivo desta dissertação foi de sequenciar e caracterizar a região codificante do RNAm da hepcidina e realizar a análise de sua expressão gênica em ovinos não portadores de processo inflamatório.

O desenvolvimento deste trabalho só foi possível graças à oportunidade do Prof. Alexandre Secorun Borges desenvolver seu pós-doutorado na Cornell University, sob a orientação da Profa. Dra. Maria Júlia Bevilaqua Felippe Flamínio. Na referida instituição foi possível o contato com outros pesquisadores, entre eles o Dr. Thomas Joseph Divers, com o qual o Prof. 
Alexandre publicou um artigo correlacionando a concentração do ferro sérico como indicador inflamatório (Borges et al., 2007). Na revisão para a elaboração deste artigo foi possível a familiarização com a hepcidina e seu efeito sobre o ferro plasmático frente ao processo inflamatório.

Dada a importância e relação da hepcidina com a concentração de ferro plasmático e inflamação sistêmica, o Prof. Alexandre Secorun Borges vislumbrou a relevância de estudos deste peptídeo em grandes animais. Quando ingressei na pós-graduação, optamos em estudar, inicialmente, as características e perfil de expressão tecidual da hepcidina em ovinos hígidos, assim este estudo poderá suportar futuras pesquisas em animais submetidos a processo inflamatório sistêmico. Para a realização deste projeto de pesquisa foi necessária a captação de recursos, uma vez que este envolveria a aquisição de animais e uma série de reagentes caros. Felizmente o financiamento foi aprovado e foi determinante para a realização deste projeto de pesquisa.

As atividades experimentais tiveram início em outubro de 2008 , onde foi realizada biópsia de fígado em animais oriundos do rebanho da Faculdade de Medicina Veterinária e Zootecnia - UNESP - Campus de Botucatu. As amostras foram então processadas e o produto sequenciado foi utilizado para predizer a sequência e caracterização da hepcidina em ovinos.

Desde meados de 2008 eu havia sido apresentado ao Prof. Dr. João Pessoa Araújo Júnior, docente do Departamento de Microbiologia e Imunologia do Instituto de Biociência de Botucatu - UNESP - Campus de Botucatu, o qual permitira que eu acompanhasse seus pós-graduandos e outras pesquisas em desenvolvimento no Laboratório de Diagnóstico Molecular. Dessa forma pude me familiarizar com a técnica de PCR em tempo real, técnica esta que utilizaria no desenvolvimento de meu projeto de pesquisa.

Em março de 2009 foram coletadas as amostras dos tecidos que foram submetidas ao estudo da análise de expressão gênica da hepcidina. Assim, em abril de 2009 comecei a realizar as reações de qPCR, sob a orientação dos professores Alexandre Secorun Borges e João Pessoa Araújo Júnior. Apesar da familiarização com a técnica, ocorreu uma série de percalços durante o desenvolvimento desta etapa do projeto. Graças à atenção e disponibilidade constantes destes dois pesquisadores, todos os problemas foram sanados e este projeto de pesquisa pode ser finalizado. 
REVISÃO DELITERATURA 


\section{REVISÃO DE LITERATURA}

\subsection{Aspectos gerais sobre a Hepcidina}

A hepcidina é um peptídeo codificado pelo gene "hepcidin antimicobrial peptide" (HAMP) (Krause et al.; 2000), e participa na regulação do metabolismo do ferro, na defesa do hospedeiro e na inflamação (Ganz, 2005). A primeira descrição deste peptídeo foi feita por Krause et al. (2000), que isolaram o peptídeo do sangue periférico de humanos e o denominaram de peptídeo antimicrobiano expresso no fígado (LEAP-1). Simultaneamente a este estudo, Park et al. (2001) isolaram o mesmo peptídeo da urina de humanos, contudo, o denominaram hepcidina (Hepc).

O fígado é o principal local de expressão do RNA mensageiro (RNAm) (Krause et al., 2000; Park et al., 2001; Pigeon et al., 2001) e síntese de hepcidina (Ganz e Nemeth, 2006). Entretanto, a síntese de hepcidina está presente, em menor grau, em neutrófilos e macrófagos (Liu et al., 2005; Sow et al., 2007), células beta pancreáticas (Kulaksiz et al., 2008), rim (Kulaksiz et al., 2005), pulmão, coração (Krause et al., 2000), medula espinhal (Park et al., 2001), estômago e intestino (Pigeon et al., 2001).

O gene codificador da hepcidina consiste em três éxons e dois íntrons, onde o terceiro éxon codifica o peptídeo ativo (Leong e Lönnerdal, 2004). Esta proteína é sintetizada como uma preproproteína, o peptídeo sinalizador é clivado levando a formação de uma proproteína, a qual é posteriormente clivada dando origem à forma ativa da hepcidina (Atanasiu et al., 2006).

A forma bioativa da hepcidina possui 25 aminoácidos (Ganz, 2003), com oito resíduos de cisteína, que formam entre si quatro pontes dissulfeto, (Park et al., 2001) altamente conservados entre as espécies (Darshan e Anderson, 2009).

Hunter et al. (2002) analisaram a forma sintética do peptídeo bioativo por ressonância magnética nuclear e estabeleceram sua estrutura e conectividade. A molécula é rica em configurações beta e forma uma estrutura em grampo, no qual os dois braços são estabilizados por três pontes dissulfeto (Ganz, 2003). A ponte dissulfeto restante é uma ligação incomum entre duas cisteínas adjacentes no giro do grampo do peptídeo (Vyoral e Petrák, 2005), com função ainda desconhecida (Atanasiu et al., 2006). Comparado com a maioria das 
pontes dissulfeto, as pontes dissulfeto formadas entre cisteínas adjacentes poderiam ter uma grande reatividade química (Ganz, 2003). Nemeth et al. (2006) observaram que a sequência N-terminal da hepcidina ativa é essencial para a função normal deste peptídeo.

Assim como outros peptídeos antimicrobianos, a hepcidina apresenta separação espacial entre as cadeias hidrofílicas, carregadas positivamente, e as cadeias hidrofóbicas, uma característica de peptídeos que rompem membranas de bactérias (Ganz, 2003). A estrutura da hepcidina é análoga a de outros peptídeos antimicrobianos (Ganz, 2006), como as defensinas, catelicidinas (Atanasiu et al., 2006) e protegrinas (Vyoral e Petrák, 2005).

A descoberta da hepcidina proveu discernimento na patogênese de vários tipos de hemocromatose hereditária e tem mudado o conhecimento da fisiopatogenia da anemia da inflamação (Ganz, 2005).

\subsection{Alvo molecular da Hepcidina}

O único alvo molecular da hepcidina conhecido é a ferroportina (FPN) (Nemeth et al., 2004b), uma proteína de membrana, com 12 supostos domínios (De Domenico et al., 2008), expressa na superfície dos macrófagos, hepatócitos, enterócitos e células placentárias (De Domenico et al., 2007). Até o momento a FPN é o único exportador celular de ferro conhecido em mamíferos (Atanasiu et al., 2006).

A região $\mathrm{N}$-terminal da hepcidina é essencial para sua interação com a FPN (Nemeth et al., 2006), além disso, o domínio de ligação da hepcidina na FPN é extremamente conservado entre as espécies (De Domenico et al., 2008). A interação direta entre hepcidina e FPN, induz a internalização celular deste complexo protéico e subsequente degradação no endolisossomo (Nemeth et al.; 2004b), provendo um mecanismo homeostático pelo qual o organismo regula os níveis de ferro plasmático e sua distribuição tecidual (Atanasiu et al., 2006).

Quando os níveis de ferro estão elevados, a síntese de hepcidina é estimulada no fígado, a qual é liberada na circulação e se liga à FPN. Desta forma, bloqueia a única via de transferência de ferro para o plasma, diminuindo assim os níveis plasmáticos de ferro (Ganz, 2005). Por outro lado, quando os níveis de ferro estão baixos, a produção da hepcidina é suprimida, deste modo 
a molécula de FPN é expressa na membrana da célula e o nível de ferro plasmático retorna a sua homeostase (Leong e Lönnerdal, 2004).

Durante processos inflamatórios e/ou infecciosos a síntese de hepcidina é estimulada (Nemeth et al., 2004a) e consequentemente ocorre a diminuição dos níveis plasmáticos de ferro (Falzacappa e Muckenthaler, 2005). De maneira similar ao excesso ou deficiência de ferro, a interação hepcidina-FPN ajuda a explicar como a inflamação e/ou infecção produzem hipoferremia (Ganz, 2005).

Para a compreensão do mecanismo de ação da hepcidina e dos fatores e vias sinalizadoras envolvidos na regulação de sua expressão, é necessária uma pequena revisão sobre o metabolismo do ferro.

\subsection{Metabolismo do ferro}

O ferro é classificado como um elemento vital para todos os organismos e possui a capacidade de receber ou doar prótons (Anderson et al., 2007). Este íon é essencial para proteínas e enzimas envolvidas no transporte de oxigênio, síntese de DNA, proliferação celular, respiração celular e reações metabólicas (Falzacappa e Muckenthaler, 2005).

Apesar do ferro ser um elemento essencial, pode ser potencialmente prejudicial quando em excesso devido a produção de espécies reativas de oxigênio (ERO) pela reação de Fenton (Viatte e Vaulont, 2009). Assim, a homeostase deste elemento exige do organismo uma regulação extremamente eficaz, entre a concentração de ferro absorvido, reciclado e excretado (Atanasiu et al., 2006). Em mamíferos, a capacidade de excreção do ferro é limitada, já que não existe via regulatória ativa para tal. Dessa forma, a homeostase sistêmica do ferro é controlada, principalmente, pela regulação entre quantidade absorvida no intestino e reciclada pelo sistema reticuloendotelial (SRE) (Constante et al., 2006).

Existem duas formas químicas do ferro, $\mathrm{Fe}^{3+}$ ou forma férrica e o $\mathrm{Fe}^{2+}$ ou forma ferrosa (Dunn et al., 2007). A maioria do ferro inorgânico da dieta está no estado férrico, e para ser absorvido pelo enterócito deve ser reduzido ao estado ferroso. Esta tarefa é realizada na superfície apical dos enterócitos pela enzima citocromo-b duodeno ferro redutase (DCytb) (Santos et al., 2009). O ferro ferroso resultante é transportado para o enterócito através de uma 
proteína transportadora de metais divalentes (DMT1) (Ganz, 2007) presente na superfície apical da célula.

O ferro absorvido pelo enterócito pode ser armazenado como ferritina ou ser transferido para o plasma (Atanasiu et al., 2006). A transferência do ferro ferroso para a circulação portal ocorre através da FPN, presente na membrana basolateral do enterócito (Dunn et al., 2007). A FPN é a única proteína responsável pelo efluxo de ferro das células (Wrighting e Andrews, 2008). Após deixar o enterócito, o ferro ferroso, para se ligar à transferrina, deve ser oxidado a ferro férrico. Esta oxidação é potencializada pela hefaestina (Heph) (Santos et al., 2009).

A transferrina é a principal proteína de transporte do ferro circulante (Dunn et al., 2007). Existem três isoformas diferentes de transferrina sérica: transferrina diférrica ou holotransferrina, transferrina monoférrica e apotransferrina (Leibman e Aisen, 1979), as quais possuem afinidades diferentes para o receptor de transferrina-1 (TFR1). A holotransferrina tem quatro vezes mais afinidade para TFR1 do que a transferrina monoférrica e 24 vezes mais afinidade que a apotransferrina (Young et al., 1984).

A ligação da transferrina com o TFR1, presente na membrana plasmática das células, forma um complexo que é endocitado. Este compartimento endossomal é ativamente acidificado por bombas de próton, levando a redução do $\mathrm{pH}$. Esta queda do pH induz a liberação do ferro férrico da transferrina, por reduzir a afinidade desta proteína com o ferro férrico (Wrighting e Andrews, 2008). A transferrina se liga apenas ao ferro férrico enquanto o DMT1, presente na membrana do endossomo, transporta para o citoplasma apenas o ferro ferroso (Dunn et al., 2007). A redução do ferro neste compartimento é realizada possivelmente pela proteína redutora "sixtransmembrane epithelial antigen of prostate 3" (STEAP3) permitindo assim o transporte do íon para fora do endossomo através da DMT1 (Atanasiu et al., 2006). Tanto a transferrina sem ferro (apotransferrina) com o TFR1 retornam a superfície da célula para um ciclo posterior. O ferro é então consumido ou armazenado na forma de ferritina e/ou hemossiderina (Santos et al., 2009). 


\subsection{Mecanismos de ação}

\subsubsection{Atividade regulatória sobre o ferro}

A hepcidina é a principal molécula que regula o metabolismo de ferro, assim, a regulação eficaz da sua síntese é de vital importância para a sobrevivência (Anderson et al., 2007). Na sobrecarga de ferro a expressão da hepcidina é induzida, visando diminuir a absorção e liberação do ferro e consequentemente os níveis circulantes deste elemento (Pigeon et al., 2001).

O envolvimento da hepcidina no metabolismo do ferro foi sugerido por Pigeon et al. (2001), que demonstraram que a sobrecarga dietética de ferro estimulava a expressão gênica da hepcidina. Por outro lado, Frazer et al. (2002) demonstraram que a deficiência dietética deste elemento inibia a expressão da hepcidina. Estudos em camundongos transgênicos demonstraram que a ausência da hepcidina levava à sobrecarga de ferro (Nicolas et al., 2001), em contrapartida, a expressão acentuada levava à grave deficiência de ferro e anemia (Nicolas et al., 2002a). Estes estudos demonstraram uma ligação direta entre hepcidina e metabolismo do ferro.

O fenótipo encontrado em camundongos "knockout" (-/-) produzidos no estudo de Nicolas et al. (2001) indicou que a hepcidina controla a absorção intestinal de ferro e a retenção de ferro dentro dos macrófagos.

Para manter o "status" de ferro corpóreo, este deve ser absorvido pelo enterócito e liberado na circulação portal, bem como ser reciclado dos eritrócitos senescentes (Fleming, 2008). Somente após a identificação da hepcidina, o mecanismo molecular envolvido no metabolismo do ferro tornouse esclarecido (Leong e Lönnerdal, 2004).

Em camundongos, existem dois genes codificadores da hepcidina (Hepc1 e Hepc2) e sua expressão é controlada pelo "Upstream stimulatory factor 2" (Usf2). Estudos utilizando camundongos Usf2 -/-, Hepc1 -/- e Hepc2 -/demonstraram que os genes Usf2 e Hepc1 estão relacionados com a regulação da homeostase do ferro (Nicolas et al., 2001; Pigeon et al., 2001).

Em roedores, durante o desenvolvimento embrionário, a expressão da hepcidina no fígado é baixa, entretanto, logo após o nascimento torna-se temporariamente elevada, provavelmente devido à resposta adaptativa à demanda metabólica de ferro (Nicolas et al., 2002b). 
Camundongos apresentando deficiência severa de ferro ao nascimento possuem elevados níveis de hepcidina. Nicolas et al. (2002b) demonstraram que somente a administração parenteral de ferro reverteu a deficiência severa de ferro encontrada nestes camundongos. Estas observações sugerem que os elevados níveis de hepcidina podem inibir tanto o transporte placentário como a captação intestinal de ferro.

A regulação do ferro pela hepcidina funciona como um mecanismo de retroalimentação permitindo a entrada de quantidade suficiente de ferro quando a demanda é elevada ou limitando a liberação de ferro no plasma nos momentos em que o aporte de ferro é suficiente (Darshan e Anderson, 2009).

Camundongos "knockout" para a transferrina apresentaram anemia e responderam a esta pela absorção máxima de ferro, assim o ferro foi acumulado no fígado, mas não pode ser utilizado para a eritropoese devido à falta da transferrina. Neste modelo a expressão da hepcidina é baixa sugerindo que a sinalização da anemia ferropriva sobrepõe a sinalização da sobrecarga de ferro ou que a transferrina ligada ao ferro é a sinalização para a síntese de hepcidina (Weinstein et al., 2002). Lin et al. (2007) observaram que a expressão da hepcidina só é estimulada pelo ferro quando este está ligado à transferrina. Esta observação sugere que o fígado utiliza a saturação da transferrina como um sinalizador do conteúdo de ferro corpóreo (Collins et al., 2008).

Todas as observações realizadas em modelos experimentais com ratos e camundongos indicam que a hepcidina inibe a absorção intestinal de ferro, bloqueia o transporte de ferro através da placenta e induz o sequestro de ferro pelos macrófagos. Quando a demanda de ferro é alta, a expressão da hepcidina está diminuída, por outro lado quando ocorre diminuição do requerimento de ferro a expressão da hepcidina está elevada (Frazer et al., 2002).

\subsubsection{Atividade antimicrobiana}

A hepcidina é ativa contra bactérias gram-positivas, bactérias gramnegativas e fungos (Krause et al., 2000), sendo parte do sistema imune inato (Ganz, 2003), o qual é a primeira linha de defesa contra infecções (Atanasiu et al., 2006). Ela contém aminoácidos que conferem uma carga total positiva e 
uma tendência de assumir uma estrutura secundária anfipática (Hunter et al., 2002). Esta propriedade confere ao peptídeo atividade antimicrobiana pela capacidade em penetrar na membrana dos microorganismos invasores (Falzacappa e Muckenthaler, 2005).

A hepcidina exerce atividade antimicrobiana modesta in vitro (Ganz, 2006). Krause et al. (2000) demonstraram que a hepcidina possui atividade antibacteriana e antifúngica em concentrações entre 10-30 $\mu \mathrm{M}$, entretanto, a concentração urinária encontrada foi de 3-30 nM. Desta forma, é improvável que ela possa exercer atividade antimicrobiana na urina ou em outros fluidos orgânicos (Ganz, 2005).

Além da função antimicrobiana, a hepcidina atua como regulador do metabolismo do ferro (Ganz, 2003). Assim, atua diretamente sobre os patógenos e/ou reduzindo a quantidade de ferro disponível a estes (Falzacappa e Muckenthaler, 2005)

\subsection{Fatores responsáveis pela regulação da expressão de Hepcidina}

A regulação da expressão da hepcidina é um mecanismo bastante complexo e pouco compreendido (Anderson et al., 2007). A expressão da hepcidina é estimulada na sobrecarga de ferro, inflamação e infecção. Em contrapartida, sua síntese é inibida na deficiência de ferro, hipóxia, expansão eritróide e anemia ferropriva (Pigeon et al. 2001, Frazer et al. 2002, Nicolas et al. 2002c, Ganz, 2003, Falzacappa and Muckenthaler, 2005, Oates and Ahmed, 2007, Fleming, 2008, Viattee and Vaulont, 2009). A expressão da hepcidina é regulada por três fatores principais: concentração de ferro plasmático, concentração de oxigênio e inflamação (Nicolas et al., 2002c).

\subsubsection{Estimuladores da síntese de Hepcidina}

A sobrecarga de ferro proveniente da dieta (Pigeon et al., 2001) ou de transfusões (Atanasiu et al., 2006) leva ao aumento da síntese da hepcidina. $O$ gene codificante da hepcidina (HAMP) não possui nenhum elemento responsivo ao ferro, sugerindo que a expressão da hepcidina não é sinalizada diretamente pelo nível de ferro corporal, mas por outras vias sinalizadoras (Atanasiu et al., 2006). 
As vias envolvidas na regulação da expressão do gene HAMP não são bem conhecidas (Ganz, 2006). Courselaud et al. (2002) identificaram na região promotora do gene HAMP, locais de ligação para fatores de transcrição "Ccaat-

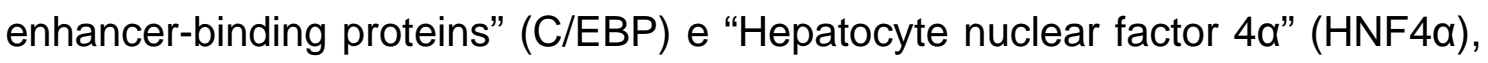
fatores conhecidos na regulação de genes específicos do fígado, e demonstraram que C/EBP induz, enquanto HNF4a reduz, a expressão do RNA mensageiro (RNAm) da hepcidina. Outras proteínas também estão envolvidas na modulação da expressão da hepcidina, estando associadas com a regulação da homeostase do ferro na hemocromatose hereditária tanto em humanos como em camundongos (Falzacappa e Muckenthaler, 2005).

Assim como outros peptídeos antimicrobianos, a síntese de hepcidina é induzida pela inflamação (Nemeth et al., 2003). Inúmeros estudos experimentais, visando esclarecer a relação entre a inflamação e a hepcidina, demonstraram que a administração de lipopolissacarídeo (LPS) (Pigeon et al., 2001; Wang et al., 2008), adjuvante de Freund (Anderson et al., 2002) e/ou óleo de turpentina (Nicolas et al., 2002a) estimularam a expressão e a síntese da hepcidina e levaram à hipoferremia (Liu et al., 2005).

A expressão do gene HAMP é modulada por citocinas produzidas em processos infecciosos e/ou inflamatórios (Atanasiu et al., 2006). Existem ainda divergências sobre quais citocinas são responsáveis pela regulação da expressão da hepcidina. Nemeth et al. (2003), demonstraram que a expressão do RNAm da hepcidina em hepatócitos tratados com IL-1, TNF- $\alpha$ e IL-6 aumentou apenas pela ação da IL-6. A mesma resposta foi observada em estudo in vivo utilizando camundongos e humanos como modelo experimental (Nemeth et al., 2004a). Lee et al. (2005) demonstraram que a transcrição da hepcidina foi estimulada em macrófagos de camundongos IL-6 -/-, sugerindo que IL-1a e IL-1ß são potentes indutores da expressão de hepcidina. Em humanos, a estimulação da síntese de hepcidina pela IL-6 é acompanhada por hipoferremia e diminuição da saturação da transferrina (Nemeth et al., 2004a). O mecanismo específico pelo qual estas citocinas estimulam a expressão da hepcidina é desconhecido (Atanasiu et al., 2006).

O estímulo da expressão da hepcidina, em resposta à inflamação e/ou infecção (Ganz, 2004), limita a biodisponibilidade de ferro para a maioria dos 
microorganismos (Radtke and O'Riordan, 2006). Nas inflamações crônicas, esse estímulo é contínuo e resulta em alterações na homeostase do ferro levando à anemia da inflamação (Ganz, 2004).

\subsubsection{Inibidores da síntese de Hepcidina}

A maioria do ferro absorvido ou reciclado é destinado para os eritrócitos em desenvolvimento, principalmente após perda sanguínea ou hipóxia (Ganz, 2006). Desta forma, a síntese de hepcidina diminui devido à anemia e/ou hipóxia (Nicolas et al., 2002a). Os níveis desta proteína diminuem e como consequência, maior serão os níveis de ferro oriundos da absorção intestinal, dos macrófagos e dos hepatócitos (Ganz, 2006).

Os fatores responsáveis pela inibição da síntese de hepcidina pela anemia podem ser mediados pela hipóxia tecidual, níveis elevados de eritropoetina, atividade eritropoética aumentada e/ou diminuição plasmática ou tecidual de ferro devido ao seu consumo por precursores eritróides (Ganz, 2006)

A hipóxia estimula o suprimento de ferro plasmático (Nicolas et al., 2002a) e, consequentemente, a eritropoese, sendo diretamente associada com a redução da produção da hepcidina (Darshan e Anderson, 2009).

Nicolas et al. (2002a) demonstraram que a hipóxia reduziu o nível de transcritos de hepcidina tanto no modelo ex vivo, utilizando células HepG2, como no modelo in vivo, utilizando camundongos não anêmicos em câmara hipobárica. Merle et al. (2007) observaram que diferentemente do fígado, no qual hipóxia resulta em inibição da expressão da hepcidina, a expressão da hepcidina no coração foi estimulada em resposta à hipóxia, sugerindo um mecanismo de proteção local contra a formação de EROs, por controlar a concentração de ferro livre no citosol.

A hipóxia leva ao aumento da absorção de ferro, entretanto, a administração de óleo de turpentina, um estímulo inflamatório que leva ao aumento da expressão da hepcidina inverteu este efeito (Nicolas 2002a). Isto sugere que quando existem estímulos combinados para a inibição ou síntese da hepcidina, ocorre a sobreposição de um deles (Falzacappa e Muckenthaler, 2005). 
A hepcidina pode constituir a ligação molecular entre a hipóxia tecidual e o aumento da absorção de ferro (Falzacappa e Muckenthaler, 2005). Em condições de normoxia e quantidade plasmática de ferro normal, uma prolilhidroxilase (PHD) dependente de ferro e oxigênio modifica a subunidade

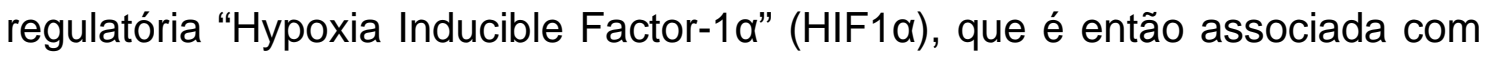
a proteína supressora do tumor de Von Hippel-Lindau (VHL), a qual promove a degradação da subunidade HIF1a. Na hipóxia tecidual ou deficiência de ferro, a PHD é inativada, ocorrendo o acúmulo da subunidade regulatória HIF1a e translocação desta até o núcleo. No núcleo, HIF1a conjuga-se com "Hypoxia Inducible Factor - 1ß" (HIF1ß) e este complexo se liga a promotores que modulam a transcrição gênica de genes relacionados à hipóxia (Peyssonnaux et al., 2008).

Peyssonnaux et al. (2007) sugeriram que a baixa concentração de oxigênio tecidual leva ao acúmulo de HIF1a, diminuindo assim a expressão da hepcidina. Entretanto, camundongos HIF1a -/- mantidos sob dieta deficiente em ferro expressaram elevados níveis de hepcidina (Weinstein et al., 2002), indicando que a ausência de HIF1 $\alpha$ afeta os mecanismos fisiológicos que regem a inibição da expressão da hepcidina durante a deficiência nutricional de ferro (Peyssonnaux et al., 2007). Braliou et al. (2008) demonstraram que a inibição in vitro das PHDs inibe a expressão da hepcidina, mesmo em condições de normoxia.

O estímulo à eritropoese pode alterar a expressão gênica da hepcidina devido à demanda acentuada de ferro ou através da hipóxia (Darshan e Anderson, 2009). Em camundongos, anemia devido à flebotomia aguda ou administração de fenil-hidrazina, a qual induz hemólise aguda, suprimem a síntese de hepcidina (Nicolas et al., 2002c; Pak et al., 2006), estimulando a absorção de ferro dentro de poucos dias (Frazer et al., 2004).

Nicolas et al.(2002c) propuseram que a inibição da síntese de hepcidina poderia ocorrer devido ao estímulo da produção de eritropoetina (EPO). Neste estudo os autores demonstraram que a administração de EPO, em camundongos, diminuiu consideravelmente a expressão gênica da hepcidina. Estudos in vitro demonstram que a EPO sinaliza a inibição da expressão da hepcidina pelo mecanismo envolvendo o fator de transcrição C/EBPa e o promotor da hepcidina (Pinto et al., 2008). Huang et al. (2009) recentemente 
propuseram, em estudo in vivo, que EPO pode inibir a expressão da hepcidina indiretamente via supressão dos sinalizadores STAT3 e SMAD4.

Tanno et al. (2007) demonstraram que o fator de diferenciação do crescimento (GDF15), durante a maturação dos eritroblastos, apresenta elevada expressão gênica. Neste mesmo estudo, hepatócitos tratados com elevadas concentrações de GDF15, apresentaram reduzida expressão de hepcidina. Vokurka et al. (2006) observaram um aumento na expressão da hepcidina, após anemia induzida por fenil-hidrazina, quando a medula óssea foi previamente suprimida por irradiação. Os níveis plasmáticos de hepcidina e de GDF15 não apresentaram correlação significante após transplante medular com células tronco em humanos (Kanda et al., 2008).

Todos estes achados sugerem que a inibição da síntese de hepcidina, pelo estímulo à eritropoese, depende indiretamente da EPO e diretamente de fatores expressos na medula óssea.

Nicolas et al. (2002a) demonstraram que a administração de ferrodextrano para correção da anemia induzida por fenil-hidrazina foi incapaz de estimular a expressão da hepcidina. Os autores ainda observaram que, apesar da sobrecarga de ferro, ocorreu a redução da expressão de hepcidina e um aumento da absorção intestinal deste elemento. Este modelo poderia contribuir para o entendimento dos mecanismos envolvidos na sobrecarga de ferro e hemosiderose nos casos de anemias crônicas com hemólise e/ou diseritropoese (Atanasiu et al., 2006).

\subsection{Principais vias envolvidas na regulação da expressão de Hepcidina}

Os estudos com hemocromatose hereditária humana $(\mathrm{HH})$ têm demonstrado que várias proteínas podem participar na regulação da expressão gênica da hepcidina. A HH é uma doença genética, na qual a absorção do ferro não é adequadamente regulada, resultando em absorção excessiva e deposição de ferro em órgãos vitais e pode ocorrer devido à mutações nos genes HFE, HFE2, HAMP, TFR2 e SLC40A1 (Santos et al., 2009). Deste modo, as proteínas codificadas por esse genes podem participar na regulação da expressão gênica da hepcidina (Anderson et al., 2007). 


\subsubsection{HFE e Hepcidina}

O gene HFE codifica uma proteína MHC de classe I não clássica, a qual após associada com $\aleph_{2}$-Microglobulina $\left(\aleph_{2} \mathrm{M}\right)$, é distribuída para a membrana plasmática (Falzacappa e Muckenthaler, 2005). A proteína HFE é expressa em todos os tecidos, mas está presente predominantemente no fígado (Zhang et al., 2004). Anderson et al. (2007) sugeriram que a proteína HFE e a holotransferrina competem pela ligação no sítio do TFR1, controlando assim, a entrada de ferro na célula (Feder et al., 1998). Dessa forma, mutações poderiam gerar alterações anômalas entre TFR1 e HFE e consequente sobrecarga de ferro (Andrews, 1999).

Estudos realizados em camundongos HFE -/- e humanos com HH tipo 1, evidenciaram baixa expressão de hepcidina (Ahmad et al., 2002; Bridle et al., 2003) e sobrecarga de ferro no fígado (Spasic et al., 2008). Entretanto, Constante et al. (2006) demonstraram que camundongos "knockout" para HFE foram capazes de aumentar a expressão de hepcidina em resposta à sobrecarga dietética de ferro, embora os níveis absolutos alcançados fossem inferiores aos alcançados pelo grupo controle recebendo a mesma dieta.

\subsubsection{TFR2 e Hepcidina}

A segunda proteína associada com a expressão da hepcidina foi um receptor de membrana do tipo 2 pertencente a família dos receptores da transferrina (TFR2) (Anderson et al., 2007). A proteína TFR2 é homóloga ao receptor TFR1 e é predominantemente expressa no fígado (Kawabata et al., 2000). A proteína TFR2 se liga à transferrina com menor afinidade que TFR1, aproximadamente 30 vezes (Kawabata et al., 2001). Sua função fisiológica está relacionada com a absorção de ferro pelos hepatócitos e funciona como um detector da saturação da transferrina plasmática (Frazer e Anderson, 2003).

Quando existem quantidades elevadas de holotransferrina, ocorre a ligação entre esta e TFR1, assim o complexo entre HFE e TFR1 é liberado e HFE pode se ligar com TFR2 (Gao et al., 2009). O complexo HFE-TFR2 poderia assim induzir a expressão de hepcidina, possivelmente através da via MAPK/ERK (Ramey et al., 2009).

Mutações na proteína TFR2 resultam em sobrecarga tecidual de ferro, indicando que esta molécula participa na regulação da homeostase do ferro 
(Roetto et al., 2001). Nemeth et al. (2005) observaram que mutações da proteína TFR2 levam à mesma produção de baixos níveis de hepcidina, sugerindo que TFR2 poderia atuar como um regulador da produção de hepcidina. Em camundongos TFR2 -/- não houve estímulo da expressão da hepcidina após sobrecarga de ferro induzida (Kawabata et al., 2005).

\subsubsection{Hemojuvelina e Hepcidina}

A hemojuvelina (HJV) é uma proteína codificada pelo gene HFE2 (Papanikolaou et al., 2004) e pertence a família das RGM ("repulsive guidance molecules"), proteínas importantes em diferentes estágios do desenvolvimento embrionário (Oldekamp et al., 2004). Esta molécula é muito expressa no músculo esquelético e no coração e menos expressa no fígado (Papanikolaou et al., 2004). Existem duas isoformas de HJV: a primeira, uma proteína de membrana ancorada a um glicosilfosfatidilinositol (GPI) e a segunda, uma isoforma solúvel (HJVs) não ancorada (Lin et al., 2005).

As BMPs ("Bone Morphogenetic Proteins") são um grupo de fatores de crescimento. Quando a BMP se liga aos receptores serina/treonina quinase tipo I e tipo II (BMPR), o complexo é ativado e estimula a fosforilação de proteínas citoplasmáticas conhecidas como SMAD. Estas proteínas fosforiladas associam-se ao mediador SMAD4, formando um complexo que será transferido até o núcleo e irá modular a expressão gênica de diversos genes (Shi e Massagué, 2003), regulando a proliferação, diferenciação, apoptose e migração celular (Zhao, 2003).

A HJV pode se ligar com o BMPR, que após ser estimulado por BMP2, BMP4 ou BMP9, promove a fosforilação das proteínas SMAD1/5/8 (Babitt et al., 2006). Estas SMADs ativadas podem se conjugar com a SMAD4, e este complexo ser transferido para o núcleo, estimulando a expressão da hepcidina (Darshan e Anderson, 2009).

Diferentes modelos tentam explicar como HJV regula a expressão da hepcidina (Atanasiu et al., 2006). Papanikolaou et al. (2004), observaram que mutações na HJV reduzem os níveis de hepcidina. Camundongos HJV -/apresentaram fenótipo de sobrecarga de ferro e ausência de expressão de hepcidina, mesmo quando os níveis de ferro da dieta estavam elevados (Niederkofler et al., 2005). Lin et al. (2005) demonstraram que o silenciamento 
do RNAm de HFE2 leva a diminuição da expressão da hepcidina. Esses estudos indicam que a HJV é essencial para a produção e regulação da expressão de hepcidina (Babitt et al., 2007) e da regulação do metabolismo do ferro (Darshan e Anderson, 2009). Camundongos SMAD4 -/- desenvolvem sobrecarga de ferro e baixa expressão gênica de hepcidina, sugerindo que SMAD4 é essencial para a produção de hepcidina (Wang et al., 2005).

A HJVs compete com a isoforma ligada à membrana, pela ligação com BMP, diminuindo assim a sinalização estimulatória para a expressão da hepcidina (Lin et al., 2007). A sobrecarga de ferro parece estar relacionada à diminuição da síntese de HJVs, em contrapartida a geração da HJVs parece estar aumentada pela hipóxia tecidual (Lin et al., 2005). A sobrecarga de ferro aliada a diminuição da síntese de HJVs levariam ao estímulo da síntese de hepcidina e diminuição do fluxo de ferro para o plasma. Por outro lado a hipóxia e a geração da HJVs levaria a diminuição da síntese de hepcidina e aumento do fluxo de ferro para o plasma.

\subsubsection{Inflamação e Hepcidina}

A inflamação, aguda ou crônica, altera a homeostase do ferro (Darshan e Anderson, 2009). Os mecanismos pelo qual esta alteração ocorre começaram a ser elucidados recentemente, e hoje sabemos que a inflamação é capaz de estimular a expressão de hepcidina e levar à hipoferremia. Um dos maiores mediadores relacionados ao aumento da expressão da hepcidina frente ao processo inflamatório é a IL-6, porém outras citocinas também estão envolvidas (Nemeth et al., 2004a; Lee et al., 2005). A sinalização da IL-6 para a célula é feita pela via sinalizadora JAK/STAT (Heinrich et al., 2003). O promotor do gene HAMP contém locais de ligação para os dímeros STAT3 fosforilado (Wrighting e Andrews, 2008). Entretanto, em camundongos SMAD4 -/-, IL-6 é incapaz de estimular a expressão da hepcidina (Wang et al., 2005), sugerindo que mais de uma via sinalizadora possa estar envolvida.

Trabalhos recentes demonstraram que a expressão da hepcidina durante a inflamação ocorre tanto em camundongos HFE -/- (Frazer et al., 2004a) como em camundongos TFR2 -/- (Lee et al., 2004), sugerindo que esta citocina pró-inflamatória estimula a síntese de hepcidina independentemente destas moléculas. 


\subsubsection{Hipóxia e Hepcidina}

O estímulo à eritropoese pode ser mediado por perda sanguínea ou hipóxia, necessitando do ferro absorvido ou reciclado (Ganz, 2006). A absorção do ferro está diretamente relacionada à diminuição da expressão da hepcidina, sendo esta a ligação molecular entre hipóxia tecidual e o aumento da absorção de ferro (Falzacappa e Muckenthaler, 2005). A região promotora da hepcidina possui locais de ligação para HIF (Ganz, 2006), portanto, é muito provável que esta via sinalizadora possa mediar a regulação da expressão gênica da hepcidina à tensão de oxigênio ambiental (Fleming, 2008). Vários trabalhos demonstraram que a hipóxia ou anemia levam à diminuição da síntese de hepcidina (Nicolas et al., 2002c; Pak et al., 2006 Peyssonnaux et al., 2007; Peyssonnaux et al., 2008). Dessa forma, parece evidente que a via sinalizadora HIF/VHL possa participar diretamente na regulação da expressão gênica da hepcidina (Fleming, 2008).

$\mathrm{O}$ artigo a seguir (capítulo dois) foi redigido em conformidade com as normas do periódico científico "Research in Veterinary Science" e teve por objetivo sequenciar, caracterizar e realizar a análise da expressão gênica da hepcidina em ovinos hígidos. 
CAPÍTULOII 


\section{IDENTIFICATION, CHARACTERIZATION AND EXPRESSION ANALYSIS OF HEPCIDIN GENE IN SHEEP}

\section{ABSTRACT}

Hepcidin is part of the innate immune system and plays a central role in the regulation of iron homeostasis. This peptide has been previously characterized in man, non-human primates, rat, mouse, dog, swine, cattle, horse, fishes, reptiles and birds but not in sheep until now. The aim of this study was to sequence, characterize and perform hepcidin gene expression analysis in different tissues collected from healthy sheep. The resulting open reading frame consisted of 249 bp predicted to encode an 82 aa peptide with a putative 23 aa signal peptide, a 34 aa pro-region and the 25 aa mature hepcidin. The deduced sequence of the sheep hepcidin precursor was mostly homologous to Bos taurus and Bubalus bubalis. Hepcidin was predominantly expressed in liver, although high expression was present in abomasum and lower level expression occurred in other tissues. These findings extend our comparative knowledge of this peptide, showing the relationship between ovine hepcidin and other mammalian hepcidins and might be helpful for additional studies on iron metabolism and inflammatory process in sheep.

Keywords: Sheep, hepcidin, mRNA, peptide, innate immunity 


\section{INTRODUCTION}

Iron plays a central role in biology (Falzacappa and Muckenthaler, 2005) and is an essential trace element for both the host and pathogen (Ong et al., 2006). Serum or plasma iron concentration is determined by the regulated release or sequestration of this element (Darshan and Anderson, 2009). During infection, iron is critical for bacterial growth and pathogenicity (Bullen, 1981). Plasma or serum iron decreases during infection or inflammation, and this may be part of the innate host defense mechanism, limiting the availability of this element to most pathogens (Burriel and Heys, 1997; Jones and Allison, 2007; Martens et al., 2007; Radtke and O'Riordan, 2006). Ewes experimentally infected with coagulase-negative staphylococci causing mastitis showed a decrease in serum iron levels one day after inoculation (Burriel and Heys, 1997). Neils et al. (2006) showed that Trypanossoma congolense infection in sheep decreased the concentration of iron in serum coinciding with the first peak of parasitaemia.

Hepcidin is a highly conserved disulfide-bonded peptide encoded by a preproprotein, which is post-translationally processed to a 25 amino acid mature peptide (Fry et al., 2004; Valore and Ganz, 2008). Hepcidin received its name because of its origin in the liver and its bactericidal properties (Park et al., 2001). Produced mainly by the liver, this peptide was shown to be the iron hormone sought for many years (Ganz, 2005; Ganz and Nemeth, 2006; Viatte and Vaulont, 2009), and it plays a central role in the regulation of iron homeostasis (Beutler, 2007). Hepcidin regulates iron storage and uptake by binding ferroportin and causing its internalization and degradation, thereby decreasing iron availability in the circulation (Andrews, 2004; Nemeth et al., 2004b; Valore and Ganz, 2008; Viatte and Vaulont, 2009). Via this mechanism, hepcidin is responsible for the hypoferremia of inflammation (Nicolas et al., 2002).

Hepcidin is part of the innate immune system (Falzacappa and Muckenthaler, 2005) and is structurally similar to other antimicrobial peptides (Atanasiu et al., 2006), which exhibit a broad range of activity against most microorganisms (Park et al., 2001). Hepcidin contains a positive total charge and a tendency to assume amphipathic secondary structures (Falzacappa and 
Muckenthaler, 2005); this property enables hepcidin to permeate the membranes of pathogens (Rossi, 2005). The role of hepcidin, acting as a link between immunity and iron-metabolism in host defense, has been previously confirmed (Falzacappa and Muckenthaler, 2005; Hilton and Lambert, 2008; Roetto and Camaschella, 2005; Segat et al., 2008).

Hepcidin gene expression is up-regulated by iron overload, inflammation and infection; in contrast, down-regulation of hepcidin synthesis occurs in situations of iron deficiency, hypoxia, erythroid expansion and iron-deficiency anaemia (Falzacappa and Muckenthaler, 2005; Viatte and Vaulont, 2009). Different studies have revealed that the expression of hepcidin is regulated by three main factors: concentration of plasma iron, oxygen concentration and inflammation (Nicolas et al., 2002).

Hepcidin gene expression is modulated by cytokines produced in infectious and/or inflammatory processes (Atanasiu et al., 2006). There are still disagreements about which cytokines are responsible for regulating the expression of hepcidin. Nemeth et al. (2003) demonstrated that the expression of hepcidin mRNA in hepatocytes treated with IL-1, TNF- $\alpha$ and IL-6 increased only in response to IL-6. The same response was observed in vivo study using mice and humans as experimental models (Nemeth et al., 2004a). Lee et al. (2005) demonstrated that hepcidin transcription was stimulated in macrophages of IL-6 knockout mice, suggesting that IL-1 $\alpha$ and IL-1ß are potent inducers of hepcidin expression. In humans, stimulation of the synthesis of hepcidin by IL-6 is accompanied by hypoferremia and decreased transferrin saturation (Nemeth et al., 2004a). Human IL-6 was induced within $3 \mathrm{~h}$ and urinary hepcidin peaked within $6 \mathrm{~h}$ after LPS injection, followed by a significant decrease in serum iron levels (Kemna et al., 2005). The specific mechanism by which these cytokines stimulate the expression of hepcidin is unknown (Atanasiu et al., 2006).

The stimulation of hepcidin expression in response to inflammation or infection (Ganz, 2004) limits the bioavailability of iron for most microorganisms (Radtke and O'Riordan, 2006). In chronic inflammation, the stimulus is continuous and results in changes in iron homeostasis leading to anemia of inflammation (Ganz, 2004).

Hepcidin has been studied and sequenced in man (Krause et al., 2000; Park et al., 2001), rat, mouse (Ilyin et al., 2003; Pigeon et al., 2001), fishes 
(Chen et al., 2005; Douglas et al., 2003; Lauth et al., 2005; Shike et al., 2004; Wang et al., 2009; Zhang et al., 2004), dog (Fry et al., 2004), swine (Sang et al., 2006), pigeons (Fu et al., 2007), bovine and cat (Hilton and Lambert, 2008), water buffalo and yak and non human primates (Segat et al., 2008); however, as far as we know, it has not been previously studied in sheep. Here we describe the sequencing and characterization of the sheep hepcidin gene, and describe its expression in several tissues of clinically healthy sheep.

\section{MATERIALS AND METHODS}

\subsection{Animals}

Sheep hepcidin gene characterization (Total RNA isolation, RT-PCR and direct sequencing) was performed using liver biopsy samples obtained from eight healthy sheep from the Sao Paulo State University herd (2 Bercamasca and 6 Santa Inês).

Hepcidin expression analysis was performed in four clinically healthy Suffolk sheep presented to a Brazilian commercial abattoir. After clinical examination was performed, blood and faecal samples were collected from these animals to assess health-status. Blood samples were collected into tubes containing ethylenediaminetetraacetic acid (EDTA) to measure packed cell volume, plasma total protein and plasma fibrinogen concentrations and with heparin to check plasma iron concentration. Plasma fibrinogen concentration (heat-precipitation refractometry method) (Stockham and Scott, 2002) was considered normal when it was within the reference values $(100-500 \mathrm{mg} / \mathrm{dL}$ ) (Aitken, 2000). Iron concentration was measured on the heparinized plasma samples with semi-automated chemistry analyzer SB-190 $\left(\mathrm{Celm}^{\circledR}\right)$ with the Ferro Cromazurol reagent $\left(\right.$ Laborlab $\left.^{\circledR}\right)$. Iron concentration was considered normal when it was within the reference values (18-48 $\mu \mathrm{mol} / \mathrm{L})$ (Aitken, 2000). Animals were dewormed 25 days prior to sample collection and faecal egg count was negative (McMaster method) at the sampling time. Samples from the same tissues described below were collected in formalin and submitted to routine HE evaluation.

Procedures were previously approved by the Sao Paulo State University Institutional Animal Care and Use Committee (177/2007). 


\subsection{RNA isolation, RT-PCR and sequence analysis}

Liver biopsy was performed with animals restrained in left lateral recumbency, and the right abdomen was soaked and lathered with $7.5 \% \mathrm{w} / \mathrm{v}$ povidone-iodine (Riodeine ${ }^{\circledR}$, Rioquímica, Brazil). An area of approximately 16 $\mathrm{cm}^{2}$ between the eighth and eleventh intercostal spaces slightly above an imaginary line from the tuber coxae to the point of the elbow was clipped, and cleaned with $4 \%$ chlorhexidine digluconate (Riohex ${ }^{\circledR}$, Rioquímica, Brazil) and $7.5 \% \mathrm{w} / \mathrm{v}$ povidone-iodine (Riodeine ${ }^{\circledR}$, Rioquímica, Brazil). Ultrasound-guided percutaneous hepatic biopsy was performed 5 minutes after a local anaesthetic (2\% lidocaine, Xylestesin ${ }^{\circledR}$, Cristália, Brazil) was injected. Biopsy samples were collected with a tru-cut biopsy needle (14 G x $200 \mathrm{~mm}$, Biomedical, Brazil) using the technique described by Ferreira et al. (1996).

Immediately after harvesting, all samples were frozen in liquid nitrogen and stored at $-80^{\circ} \mathrm{C}$ until processing. Total RNA was isolated from the liver samples using the RNeasy ${ }^{\circledR}$ Mini Kit (QIAGEN Inc. Valencia, CA, USA), following the manufacturer's instructions. The relative purity and quality of the isolated RNA was determined by spectrometry (Nanodrop ${ }^{\circledR} 1000$ Spectrophotometer, Thermo Scientific $\left.{ }^{T M}\right)$. Briefly, total RNA was treated with DNase I Amp Grade (Invitrogen, Carlsbad, CA, USA) to eliminate genomic DNA from the samples. Then, $1 \mu \mathrm{g}$ of the RNA samples was primed with random hexamers and used to synthesize first strand cDNAs using the ImProm-IIM Reverse Transcription System (Promega, Madison, WI, USA) following the manufacturer's instructions.

A set of primers used to get the full coding mRNA hepcidin sequence as designed with PrimerQuest ${ }^{\circledR}$ software from Integrated DNA Technologies Inc (IDT, Coralville, IA, USA) using a partial sequence obtained from fragments of the ovine EST database (http://www.sheephapmap.org/isgc index.htm) searched with the AgResearchBLAST (tblastn) program with available hepcidin mRNA sequences of cattle, dogs, pigs, humans, rats and mice. Primer sequences are presented in Table 1.

PCR was performed in duplicate with GoTaq $^{\circledR}$ Green Master Mix (Promega, Madison, WI, USA) to amplify the full-length coding sequence of the sheep hepcidin. The $50 \mu \mathrm{l}$ PCR reaction contained $0.3 \mu \mathrm{M}$ of each of the 
forward and reverse primer, $1 \mu \mathrm{l}$ template cDNA, $25 \mu \mathrm{l} \mathrm{GoTaq}{ }^{\circledR}$ Green Master Mix and nuclease-free water to complete the final volume. Amplification conditions were as follows: initial denaturation at $95^{\circ} \mathrm{C}$ for $5 \mathrm{~min}$ followed by 40 cycles at $95^{\circ} \mathrm{C}$ for $30 \mathrm{sec}$, annealing at $55^{\circ} \mathrm{C}$ for $30 \mathrm{sec}$, and extension at $72^{\circ} \mathrm{C}$ for $1 \mathrm{~min}$, followed by a final extension at $72^{\circ} \mathrm{C}$ for $5 \mathrm{~min}$. PCR was performed using a Mastercycler ${ }^{\circledR}$ pro S (Eppendorf, Hauppauge, NY, USA). Gel electrophoresis using $1.5 \%$ agarose was carried out to verify the correct fragment length (400 base pairs [bp]) using the GelRed ${ }^{\mathrm{TM}}$ Nucleic Acid Gel Stain (Biotium, Halward, CA, USA). Gel documentation was performed using an ImageQuant ${ }^{\circledR}$ imager 4000 (GE Healthcare, Piscataway, NJ, USA).

The PCR product was purified with Invisorb ${ }^{\circledR}$ DNA CleanUp (Invitek, Berlin, Germany), following the manufacturer's instructions. DNA yield and quality were spectrophotometrically evaluated at 260/280 nm (NanoDrop, Thermo ${ }^{\circledR}$ Scientific, Wilmington, DE, USA) before sequencing. Automated direct sequence analysis (MegaBACE 1000, Amersham Biosciences, Dyenamic ET Dye Terminator kit using software Sequence Analyzer - 3.0) was performed in duplicate using the same primers previously described for hepcidin amplification (Table 1). The sequences and eletropherograms obtained were analyzed using Sequencher $^{\circledR} 4.8$ software (Gene Codes) and aligned to verify sequence homology against available sequences from the NCBI GenBank (http://www.blast.ncbi.nlm.nih.gov/Blast.cgi). The putative amino acid sequences were analyzed for the presence of signal peptides using CLC Main Workbench software (http://www.clcbio.com) (Nielsen et al., 1997). Multiple sequence alignments were performed using the CLUSTALW 2.0 program, and the MEGA4 program (Tamura et al., 2007) was used to calculate identities among different hepcidin sequences. Mature peptide positive charges, putative molecular weight and isoelectric point were predicted using CLC Main Workbench software (http://www.clcbio.com) (Nielsen et al., 1997). Phylogenetic analysis of nucleotide and derived hepcidin amino acid sequences were inferred using the Neighbor-Joining method (Saitou and Nei, 1987), complete deletion of gaps, and 1000 bootstrap interactions (Felsenstein, 1985) to determine the evolutionary relationship of sheep hepcidin with that of other species. 


\subsection{Expression analysis of sheep hepcidin by real-time PCR}

Abomasum, bladder, bone marrow, cerebellum, cerebral cortex, duodenum, heart, kidney, liver, lung, lymph node, muscle and spleen tissues were aseptically collected immediately after death from all animals. All tissue samples, except the bone marrow, were immediately frozen in liquid nitrogen and stored at $-80^{\circ} \mathrm{C}$ until processing. The bone marrow sample was collected before the death of sheep by sternal aspiration (Van Merris et al., 2001).

Total RNA was isolated from tissues (100 mg) using the acid guanidiumphenol chloroform technique (TRIzol ${ }^{\circledR}$ Reagent). Total RNA from bone marrow sample was immediately isolated after harvesting using QIAamp RNA Blood Mini Kit $\left(Q^{\text {iagen }}{ }^{\circledR}\right)$, following the manufacturer's instructions. The relative purity and quality of the isolated RNA was determined by spectrometry and the ratio of A260nm to $A 280 \mathrm{~nm}$ exceeded 2.0 for all preparations. To ensure complete removal of traces of genomic DNA, $1 \mu \mathrm{g}$ of total RNA was incubated with DNase I Amp Grade (Invitrogen ${ }^{\circledR}$ ). First-strand cDNA synthesis was performed with $450 \mathrm{ng}$ of total RNA per $60 \mu \mathrm{l}$ of reaction using ImProm-II ${ }^{\mathrm{TM}}$ Reverse Transcription System, following manufacturer's instructions.

Relative quantification of basal sheep hepcidin mRNA was performed using a standard curve based method for relative real-time PCR data processing (Larionov et al., 2005) with a 7300 Real-Time PCR Systems (Applied Biosystems, USA) and Power SYBR® Green PCR Master Mix. Sheep hepcidin and $\beta$-actin primers were designed using PrimerQuest ${ }^{\circledR}$ software from Integrated DNA Technologies Inc.

Primer sets used in the q-PCR (amplifying an $108 \mathrm{bp}$ fragment of the sheep hepcidin mRNA and an 82 bp fragment of the Ovis aries $\beta$-actin mRNA, endogenous mRNA control) are presented in Table 1.

Each quantitative PCR ( $q-P C R$ ) reaction was set in duplicate in a total of $20 \mu \mathrm{l}$ each, which contained $0.3 \mu \mathrm{M}$ of each forward and reverse primer, $2 \mu \mathrm{l}$ of template cDNA, $10 \mu \mathrm{l}$ qPCR master mix and $6.8 \mu \mathrm{l}$ nuclease-free water. In addition, a "no template" control in duplicate was included on each plate to prove that amplicon contamination was absent. PCR conditions were: initial denaturation at $95{ }^{\circ} \mathrm{C}$ for $10 \mathrm{~min}$ and 40 cycles at $95^{\circ} \mathrm{C}$ for $15 \mathrm{sec}$ and $60{ }^{\circ} \mathrm{C}$ for $60 \mathrm{sec}$, followed by a melting curve. Amplification of specific transcripts was confirmed by melting curve profiles generated at the end of each run. 
Basal expression of sheep hepcidin gene was normalized with $O$. aries $\beta$-actin mRNA. In each plate a standard curve was made using serial tenfold dilution of both cDNAs used as template in the qPCR reactions. For each animal, the mean basal expression of liver hepcidin received the relative value of 1.0 and concentrations in all other tissues were normalized proportionately.

\subsection{Statistics}

Statistical analysis using ANOVA and the Tukey post-test were performed with SAS software 9.2 (SAS Institute, Cary, NC, USA) to determine statistical significance between means of hepcidin expression in different tissues. A P value of $<0.05$ was considered to be statistically significant.

\subsection{Accession numbers}

The accession number of the mRNA and protein sequence indentified in the GenBankTM and used herein are: hepcidin (Bos taurus), NM_001114508.1 and NP_001107980.1; hepcidin (Bubalus bubalis), EU399814 and ABY81280.2; hepcidin (Canis lupus familiaris), NM_001007140.1 and NP_001007141.1, GenelD: 492281; hepcidin (Sus scrofa), NM_214117 and NP_999282.1, GenelD: 397207; hepcidin (Equus caballus), GQ_253624 hepcidin (Homo sapiens), NM_021175.2 and NP_066998.1, GenelD: 57817; hepcidin (Rattus norvegicus), NM_053469.1 and NP_445921.1, GeneID: 84604; hepcidin (Mus musculus), NM_032541.1 and NP_115930.1, GenelD: 84506; beta actin mRNA (Ovis aries), NM_001009784 and NP_001009784, GenelD: 443052.

\section{Results}

\subsection{Identification and characterization of sheep hepcidin cDNA}

Primers used for identification and characterization of the ovine hepcidin mRNA amplified a fragment of $400 \mathrm{bp}$ which was directly sequenced. The sequence obtained was blasted (http://www.ncbi.nlm.nih.gov) against cattle, water buffalo and swine genome sequences deposited in GenBank ${ }^{T M}$, confirming that the product was hepcidin, and suggesting that it consists of three exons and two introns (Fig. 1) similarly to other mammals (llyin et al., 2003; Krause et al., 2000; Park et al., 2001; Pigeon et al., 2001; Segat et al., 
2008) and fishes (Chen et al., 2005; Douglas et al., 2003; Shike et al., 2004; Zhang et al., 2004).

The putative sheep hepcidin mRNA fragment included an open reading frame of 249 nucleotides. The open reading frame (ORF) of the hepcidin sequence obtained and the deduced amino acid sequence are reported in Fig. 1a. The peptide sequence of sheep hepcidin consists of 82 amino acids (aa) with a putative 23 aa signal peptide, a 34 aa pro-region and the 25 aa mature hepcidin (Fig. 1b).

Sheep hepcidin has a putative signal peptide cleavage site between glycine $\left(\mathrm{G}^{23}\right)$ and serine $\left(\mathrm{S}^{24}\right)$ and a putative propeptide cleavage recognition site composed by the motif LQRRRR (52-57). The first six amino acids (58-63), with the presence of histidine $(\mathrm{H})$ in position 60 , observed in mature hepcidin are highly conserved among mammalian species, except in rat and mouse where an asparagine $(\mathrm{N})$ is substituted for the conserved histidine. Eight conserved cysteine $(\mathrm{C})$ residues in the mature hepcidin as well as an additional cysteine residue at position 11 of the signal peptide were also found in sheep hepcidin. The mature peptide was predicted to have 2.08 positive charges at $\mathrm{pH}$ 7.0 and to have a putative molecular weight of $2.7 \mathrm{kDa}$ and an isoelectric point of 8.68 .

Hepcidin amino acid sequences, from nine mammalian species, were aligned using the CLUSTAL X program (Larkin et al., 2007), and phylogenetic analyses were conducted using MEGA4 (Tamura et al., 2007) (Fig. 2). The experimentally determined sheep hepcidin sequence exhibited $93 \%$ identity to B. taurus and B. bubalis, $82 \%$ to S. scrofa, $76 \%$ to E. caballus, $71 \%$ to $C$. familiaris, $69 \%$ to $H$. sapiens, $58 \%$ to $M$. musculus and $56 \%$ to $R$. norvergicus (Fig. 3). Comparison of each region of sheep hepcidin showed that the putative 25 aa mature peptide of sheep hepcidin is $92 \%$ identical to cattle and water buffalo hepcidin, $88 \%$ identical to porcine hepcidin, $80 \%$ identical to canine and human hepcidin, $76 \%$ identical to equine and mouse hepcidin and $64 \%$ identical to rat hepcidin (Fig. 4), while the sheep signal peptide exhibited $92 \%$ identity to cattle and water buffalo; $74 \%$ to porcine, equine and human; $70 \%$ to rat and mouse and $61 \%$ to canine hepcidin, and the sheep pro-region exhibited $95 \%$ identity to cattle and water buffalo, $83 \%$ to porcine, $77 \%$ to equine, $71 \%$ to canine, $56 \%$ to human, $42 \%$ to rat and $36 \%$ to mouse hepcidin. 


\subsection{Expression analysis of sheep hepcidin by qPCR}

The mRNA levels for hepcidin were examined by qPCR in a variety of sheep tissues using $\beta$-actin as the reference gene. The tissue expression profile showed that the sheep hepcidin transcript is predominately expressed in liver with similar cycle threshold (CT) values obtained for $\beta$-actin housekeeping gene in this tissue. The relative concentration of mRNA compared to liver right lobe tissue (mean concentration 1.0) was $7.2 \times 10^{-3}$ (abomasum), $2.1 \times 10^{-3}$ (duodenum), $1.8 \times 10^{-3}$ (lung), $2.9 \times 10^{-4}$ (heart), $2.3 \times 10^{-4}$ (bladder), $7.7 \times 10^{-5}$ (lymph node), $5.7 \times 10^{-5}$ (kidney), $4.4 \times 10^{-5}$ (muscle), $3.9 \times 10^{-5}$ (spleen), $2.0 \times$ $10^{-5}$ (cerebellum) and $3.2 \times 10^{-6}$ (bone marrow).

When hepcidin expression was compared among liver lobes, it was observed that no statistically significant differences were present among the right (mean concentration 1.0), left $\left(9.5 \times{ }^{10-1}\right)$ and caudate $\left(4,3 \times 10^{-1}\right)$ lobes; however expression in the quadrate (2.5) lobe was significantly higher than that observed in other lobes.

Initial comparison of hepcidin expression among all tissues showed that its expression in the liver was significantly higher than its expression in other tissues, and it did not reveal significant differences in expression levels among other tissues. As the expression in other tissues was low, a second analysis was performed, without including hepatic values (Table 2). This analysis showed that hepcidin expression in abomasum was significantly higher than other tissues, expression in duodenum was similar to lung and significantly higher than other tissues and expression in lung was significantly higher than heart, bladder, lymph node, kidney, muscle, spleen, cerebellum, bone marrow and cerebral cortex.

Expression of hepcidin in duodenum was higher than that in lung, although the difference was not statistically significant. Hepcidin expression in heart and bladder were similar, and although expression in these tissues was higher than that in lymph node, kidney, muscle, spleen and cerebellum, expression differences among these tissues were not statistically significant. Hepcidin expression in bone marrow was very low, and expression of hepcidin in samples of cerebral cortex was not detected. 


\section{Discussion}

Hepcidin is highly expressed in mammalian hepatocytes (Fry et al., 2004; Krause et al., 2000; Nemeth et al., 2003; Nicolas et al., 2002; Park et al., 2001; Sang et al., 2006); therefore, sequencing was performed using liver tissue from clinically healthy sheep. The primers designed to amplify the putative sheep hepcidin sequence yielded a product of approximately $400 \mathrm{bp}$, which was directly sequenced.

The resulting ORF consisted of 249 bp predicted to encode an 82 aa peptide. Ovine hepcidin has four amino acids less than horses, three less than dogs (Fry et al., 2004), two less than humans (Krause et al., 2000; Park et al., 2001) and rats (Pigeon et al., 2001), one less than in mice (Pigeon et al., 2001) and the same number compared to cattle (Hilton and Lambert, 2008), water buffalo and pigs (Sang et al., 2006). The predicted genomic organization of the ovine hepcidin gene in three exons and two introns is similar to that reported in mammalian and fishes hepcidins (Chen et al., 2005; Douglas et al., 2003; Hilton and Lambert, 2008; Ilyin et al., 2003; Krause et al., 2000; Park et al., 2001; Pigeon et al., 2001; Segat et al., 2008; Shike et al., 2004; Wang et al., 2009; Zhang et al., 2004).

Phylogenetic analysis showed similarity with other known hepcidin amino acid sequences. When the mature sheep hepcidin peptide was compared with mature hepcidin from other species, higher identity was observed with cattle, water buffalo, and pigs. Hilton and Lambert (2008) observed that the signal peptide and active sequences are the most conserved among mammalian species and that the propeptide region showed much greater variability. In our study, after comparing hepcidin amino acid sequence with humans, cattle, water buffalos, pigs, horses, dogs, rats and mice sequences, it was observed that mature ovine hepcidin and signal peptide were also more conserved when compared to the propeptide region.

Mature ovine hepcidin presents eight cysteines at absolutely conserved positions across mammalian species (Fry et al., 2004; Hilton and Lambert, 2008; Krause et al., 2000; Park et al., 2001; Sang et al., 2006; Wang et al., 2009). These eight conserved residues are important for disulfide bonding (Fry et al., 2004) and form a $\beta$-sheet shape with a hairpin loop (Hunter et al., 2002), which leads to a marked amphipathic peptide structure, a hallmark of many 
antimicrobial peptides, like a $\beta$-defensin (Falzacappa and Muckenthaler, 2005; Taylor et al., 2007) and strongly influences antibacterial and cytotoxic properties (Klüver et al., 2005).

The first six amino acids prior to the first cysteine found in mature ovine hepcidin were identical to the other hepcidins, except for mouse and rat. This sequence appears to be essential for hepcidin-ferroportin binding (Hilton and Lambert, 2008) and subsequent internalization and degradation of this protein. The similarity of these six amino acids suggests that sheep hepcidin-ferroportin binding and subsequent events occur as previously reported for other hepcidins (De Domenico et al., 2007; Nemeth et al., 2004b).

Many biologically active proteins and peptides are initially synthesized as inactive precursors, which are post-translationally modified by a proprotein convertases (PCs) to generate the mature molecule (Duckert et al., 2004; Nakayama, 1997; Steiner, 1998; Wise et al., 1990,). Hepcidin preproprotein undergoes two cleavages (the signal peptide then the propeptide) and is then rapidly secreted from the cell (Valore and Ganz, 2008). The predicted cleavage site for the signal peptide of hepcidin is conserved among sheep, cattle, water buffalo, pigs, horses and humans; however, in the first five species, the putative signal peptide is formed by 23 amino acids, one amino acid less than human hepcidin. Hilton and Lambert (2008) showed that most eutherian mammals share a conserved arginine/lysine pro-peptide cleavage recognition site formed either by the RXRR or RXKR sequence motif in hepcidin propeptide. The ovine hepcidin sequence described here has a putative propeptide cleavage recognition site composed of LQRRRR (P6-P1 position, respectively). Active human hepcidin is generated by removal of the proregion, principally by the proprotein convertase furin (Valore and Ganz, 2008). Furin preferentially recognizes sites containing the sequence motif $\mathrm{R}-X-[\mathrm{R} / \mathrm{K}]-\mathrm{R} \downarrow$, where $X$ indicates any amino acid residue, $[\mathrm{R} / \mathrm{K}]$ indicates either an arginine or lysine residue, and the arrow $(\downarrow)$ indicate the cleavage site (Duckert et al., 2004; Fuller et al., 1989; Nakayama, 1997). The presence of the arginine at positions 1, 2 and $4(\mathrm{P} 1, \mathrm{P} 2, \mathrm{P} 4)$ suggests that furin may also share the proprotein convertase activity in ovine hepcidin. 
Real-time PCR was performed with primers designed using the sequenced ovine hepcidin gene and the relative expression of ovine hepcidin mRNA was calculated using standard curve method (Larionov et al., 2005). Expression analysis showed that expressed profile of ovine hepcidin in liver was very high and similar to that of $\beta$-actin, indicating that hepcidin was expressed in the manner of a housekeeping gene in liver. This was consistent with the findings of hepatic hepcidin expression in other species (Krause et al., 2000; Oliveira Filho et al., 2009). Other authors have shown that hepcidin is synthesized predominantly in liver and plays a central role in iron metabolism in other mammalian species (Park et al., 2001; Pigeon et al., 2001; Nicolas et al., 2002; Fry et al., 2004; Bekri et al., 2006; Sang et al., 2006).

Although the liver has a uniform gross appearance there is increasing evidence of functional heterogeneity among individual liver lobes, and within different regions within the same lobe (Irwin et al., 2005). Cox et al. (2006) showed significant differences in the expression of 875 genes between left and right liver lobes by array analysis, suggesting functional differences among liver lobes. In our study hepcidin expression was compared among liver lobes and it was observed that expression in the quadrate lobe was significantly higher than that observed in other lobes. Nevertheless, we select the right liver lobe for normalizing the relative concentration of the other tissues due to the fact that this is the lobe typically accessed for percutaneous liver biopsy.

Relative expression of hepcidin mRNA in several tissues of clinically normal sheep was lower than that found in liver. However, among those tissues, we observed significantly higher expression in abomasum, duodenum and lung, which were approximately 139, 481 and 561 times less abundant than liver, but significantly higher than heart, bladder, limph node, kidney, muscle, spleen, cerebellum and bone marrow. Gastrointestinal tract tissues are continuously exposed to antigens (Moncada et al., 2003). Also, sheep are sensitive to gastrointestinal nematode parasitism (Miller and Horohov, 2006), therefore the higher expression of hepcidin in abomasum and duodenum suggests that this peptide may be important in local innate immunity, acting as a local antimicrobial peptide and/or playing a role in iron metabolism. Previous studies showed high levels of hepcidin transcripts in intestine of fish (Zhang et al., 2004; Chen et al., 2005; Liu et al., 2009; Wang et al., 2009) and low levels in intestine 
of pigs (Sang et al., 2006) and duodenum of horses (Oliveira Filho et al., 2009). Our results also showed that in lung, hepcidin was expressed almost 561 times less than in liver. Lung exhibited the highest level of hepcidin expression compared to other tissues, exceeded only by liver, abomasum and duodenum. This is an usual result considering previous reports have shown that hepcidin is expressed in lung (Krause et al., 2000; Pigeon et al., 2001; Douglas et al., 2003; Ilyin et al., 2003; Fry et al., 2004; Oliveira Filho et al. 2009).

In our study, we detected low levels of hepcidin transcripts in heart, bladder, lymph node, kidney, muscle, spleen, cerebellum and bone marrow and differences in expression levels among these tissues were not significant. Hepcidin expression in those tissues was lower than in liver (Pigeon et al., 2001; Ilyin et al., 2003; Fry et al., 2004; Chen et al., 2005; Sang et al., 2006; Merle et al., 2007; Wang et al., 2009). Previous studies showed that the hepcidin expression in heart was abundant and widely distributed (Chen et al., 2005; Merle et al., 2007; Wang et al., 2009). However other studies demonstrated that heart hepcidin expression was weakly detectable (Pigeon et al., 2001; Ilyin et al., 2003). Oliveira Filho et al. (2009) also observed that the hepcidin expression values were found in lower levels in bladder. Several studies have demonstrated that the expression of hepcidin in the muscle is very low (Ilyin et al., 2003; Chen et al., 2005; Fu et al., 2007; Oliveira Filho et al., 2009). Similarly to these observations, expression of hepcidin by real-time PCR analysis was detectable at low levels in heart, bladder and muscle.

In the present study, hepcidin expression in spleen was detectable at low levels consistent with the findings of Wang et al. (2009), but contrasting with those of Chen et al. (2005) and Fu et al. (2007), that showed abundant splenic expression of hepcidin. Sang et al. (2006) showed that hepcidin transcripts were detected in bone marrow and lymph node, and our study confirm this observation.

Zechel et al. (2006) demonstrated that murine pro-hepcidin/hepcidin was widely distributed throughout the brain (including cerebellum). In the study herein, ovine mRNA hepcidin transcription was limited to cerebellum. Fu et al. (2007) also observed no hepcidin expression in brain. However, Chen et al. (2005) and Wang et al., (2009) showed that hepcidin is expressed in brain at very low levels. 
Park et al. (2001) identified hepcidin, which processed form was found in urine. More recently, other studies showed the hepcidin expression profile in kidney (Fry et al., 2004; Kulaksiz et al., 2005). Our data also showed renal expression of hepcidin; however, renal hepcidin was approximately 17,494 times less abundant than hepatic hepcidin.

The lowest hepcidin expression values were found in cerebellum and bone marrow. In our study, heart, bladder, lymph node, muscle, spleen, cerebellum and bone marrow hepcidin expression was 3,495; 4,444; 13,038; 22,$673 ; 25,368 ; 49,822$ and 312,203 times less than liver, respectively.

In summary, we have sequenced and characterized the mRNA encoding ovine hepcidin (GenBankTM accession GQ901053) and analyzed its expression using real-time PCR. These findings extend our comparative knowledge showing the relationship between ovine hepcidin and other mammalian hepcidins. Hepcidin was predominantly expressed in liver. Despite lower levels of expression occurred in other tissues, the most notable levels were found in abomasum. This is the first report to describe the hepcidin sequence and expression pattern in clinically healthy sheep which might support future studies dealing with inflammation and iron homeostasis.

\section{Acknowledgements}

The present research was supported by Ministério da Ciência e Tecnologia and Conselho Nacional de Desenvolvimento Científico e Tecnológico - MCT/CNPq (478621/2007-8). The first author received a scholarship from Coordenação de Aperfeiçoamento de Pessoal de Nível Superior - CAPES, and the last author has a grant from Conselho Nacional de Desenvolvimento Científico e Tecnológico - CNPq.

\section{Conflicts of interest}

We declare that there is no financial conflict of interest or relationships with other people or organizations that could inappropriately influence this work. 


\section{References}

Aitken, I. D., 2000. Diseases of Sheep. 4th ed. Iowa, Blackwell Publishing, 603. Andrews, N.C., 2004. Anemia of inflammation: the cytokine-hepcidin link. J. Clin. Invest. 113, 1251-1253.

Atanasiu, V., Manolescu, B., Stoian, I., 2006. Hepcidin - central regulator of iron metabolism. Eur. J. Haematol. 78, 1-10.

Bekri, S., Gual, P., Anty, R., Luciani,N., Dahman, M., Ramesh, B., Iannelli, A., Staccini-Myx, A., Casanova, D., Amor, I. B., Saint-Paul, M., Huet, P., Sadoul, J., Gugenheim, J., Srai, S. K. S., Tran, A., Marchand-Brustel, Y. L., 2006. Increased Adipose Tissue Expression of Hepcidin in Severe Obesity Is Independent From Diabetes and NASH. Gastroenterology.131, 788-796.

Beutler, E., 2007. Iron storage disease: Facts, fiction and progress. Blood. Cells. Mol. Dis. 39, 140-147.

Bullen, J.J., 1981. The significance in iron in infection. Rev. Infect. Dis. 3, 11271138.

Burriel, A. R., Heys, V., 1997. Serum and milk iron levels during sheep intramammary infection caused by coagulase- negative staphylococci. Biol. Trace. Elem. Res. 59, 153-158.

Cox, L. A., Schlabritz-Loutsevitch, N., Hubbard, G. B.; Nijland, M.J.; McDonald, T. J., Nathanielsz, P. W., 2006. Gene expression profile differences in left and right liver lobes from mid-gestation fetal baboons: a cautionary tale. J. Physiol. 572.1, 59-66.

Chen, S.L., Xu, M.Y., Ji, X.S., Yu, G.C., Liu, Y., 2005. Cloning, Characterization, and Expression Analysis of Hepcidin Gene from Red Sea Bream (Chrysophrys major). Antimicrob. Agents Chemother. 49, 1608-1612.

Darshan, D., Anderson, G.J., 2009. Interacting signals in the control of hepcidin expression. Biometals. 22, 77-87.

De Domenico, I., Ward, D.M., Patti, M.C.B., Jeong, S.Y., David, S., Musci, G., Kaplan, J., 2007. Ferroxidase activity is required for the stability of cell surface ferroportin in cells expressing GPI-ceruloplasmin. Embo. J. 26, 2823-2831.

Douglas, S.E., Gallant, J.W., Liebscher, R.S., Dacanay, A., Tsoi, S.C.M., 2003. Identification and expression analysis of hepcidin-like antimicrobial peptides in bony fish. Dev. Comp. Immunol. 27, 589-601. 
Duckert, P., Brunak, S., Blom, N., 2004. Prediction of proprotein convertase cleavage sites. Protein. Eng. Des. Sel. 17, 107-112.

Falzacappa, M.V.V., Muckenthaler, M.U., 2005. Hepcidin: Iron-hormone and anti-microbial peptide. Gene. 364, 37-44.

Felsenstein, J., 1985. Confidence limits on phylogenies: An approach using the bootstrap. Evolution. 39, 783-791.

Ferreira, A.V., Van der Merwe, H.J., Slippers, S.C., 1996. A technique for obtaining liver biopsies from mature sheep. Small. Rumin. Res. 22, 89-92.

Fry, M.M., Liggett, J.L., Baek, S.J., 2004. Molecular cloning and expression of canine hepcidin. Vet. Clin. Pathol. 33, 223-227.

Fu, Y.M., Li, S.P., Wu, Y.F., Chang, Y.G., 2007. Identification and expression analysis of hepcidin-like cDNAs from pigeon (Columba livia). Mol. Cell. Biochem. 305, 191-197.

Fuller, R.S., Brake, A.J., Thorner, J., 1989. Intracellular targeting and structural conservation of a prohormone-processing endoprotease. Science. 246, 482486.

Ganz, T., 2004. Hepcidin in iron metabolism. Curr. Opin. Hematol. 11, 251-254.

Ganz, T., 2005. Hepcidin - a regulator of intestinal iron absortion and iron recycling by macrophages. Best. Pract. Res. Clin. Haematol. 18, 171-182.

Ganz, T., Nemeth, E., 2006. Iron imports IV. Hepcidin and regulation of body iron metabolism. Am. J. Physiol. Gastrointest. Liver Physiol. 290, 199-203.

Hilton, K.B., Lambert, L.A., 2008. Molecular evolution and characterization of hepcidin gene products in vertebrates. Gene. 415, 40-48.

Hunter, H.N., Fulton, D.B., Ganz, T., Vogel, H.J., 2002. The solution structure of human hepcidin, a peptide hormone with antimicrobial activity that is involved in iron uptake and hereditary hemochromatosis. J. Biol. Chem. 277, 3759737603.

Ilyin, G., Courselaud, B., Troadec, M.B., Pigeon, C., Alizadeh, M., Leroyer, P., Brissot, P., Loréal, O., 2003. Comparative analysis of mouse hepcidin 1 and 2 genes: evidence for different patterns of expression and co-inducibility during iron overload. Febs. Lett. 542, 22-26. 
Irwin, R. D., Parker, J. S., Lobenhofer, E. K., Burka, L. T., Blackshear, P. E., Vallant, M. K., Lebetkin, E. H., Gerken, D. F., Boorman, G. A., 2005. Transcriptional Profiling of the Left and Median Liver Lobes of Male F344/N Rats Following Exposure to Acetaminophen. Toxicol. Pathol. 33, 111-117. Jones, M. L., Allisson, R. W., 2007. Evaluation of the ruminant complete blood cell count. Vet. Clin. North. Am. Food. Anim. Pract. 23, 377-402.

Kemna, E., Pickkkers, P., Nemeth, E., van de Hoeven, H., Swinkels, D., 2005. Time-course analysis of hepcidin, serum iron, and plasma cytokine levels in humans injected with LPS. Blood 106, 1864-1866.

Klüver, E., Schulz-Maronde, S., Scheid, S., Meyer, B., Forssmann, W. G., Adermann, K, 2005. Structure-Activity Relation of Human â-Defensin 3: Influence of Disulfide Bonds and Cysteine Substitution on Antimicrobial Activity and Cytotoxicity. Biochem. 44, 9804-9816.

Krause, A., Neitz, S., Marget, H.J., Schutz, A., Forssmann, W.G., SchulzKnappe, P., Adermann, K., 2000. LEAP-1, a novel highly disulfide-bonded human peptide, exhibits antimicrobial activity. Febs. Lett. 480, 147-150.

Kulaksiz, H., Theilig, F., Bachmann, S., Gehrke, S.G., Rost, D., Janetzko, A., Cetin, Y., Stremmel, W., 2005. The iron-regulatory peptide hormone hepcidin: expression and cellular localization in the mammalian kidney. J. Endocrinol. 184, 361-370.

Larionov, A., Krause, A., Miller, W., 2005. A standard curve based method for relative real time PCR data processing. BMC Bioinform. 6, 62.

Larkin, M.A., Blackshields, G., Brown, N.P., Chenna, R., McGettigan, P.A., McWilliam, H., Valentin, F., Wallace, I.M., Wilm, A., Lopez, R., Thompson, J.D., Gibson, T.J., Higgins, D.G., 2007. Clustal W and Clustal X version 2.0. Bioinformatics. 23, 2947-2948.

Lauth, X., Babon, J. J., Stannard, J. A., Singh, S., Nizet, V., Carlberg, J. M., Ostland, V. E., Pennington, M. W., Norton, R. S., Westerman, M. E., 2005. Bass hepcidin synthesis, solution structure, antimicrobial activities and synergism, and in vivo hepatic response to bacterial infections. J. Biol. Chem. 280, 9272-9282.

Lee, P.; Peng, H.; Gelbart, T,. Wang, L.; Beutler, E., 2005. Regulation of hepcidin transcription by interleukin-1 and interleukin-6. Proc. Natl. Acad. Sci. 102, 1906-1910. 
Liu, F., Li, J., Yue, G., Fu, J., Zhou, Z., 2009. Molecular cloning and expression analysis of the liver-expressed antimicrobial peptide 2 (LEAP-2) gene in grass carp. Vet. Immunol. Immunopathol. 133, 133-143.

Martens, R.J., Mealey, K., Cohen, N.D., Harrington, J.R., Chaffin, M.K., Taylor, R.J., Bernstein, L.R., 2007. Pharmacokinetics of gallium maltolate after intragastric administration in neonatal foals. Am. J. Vet. Res. 68, 1041-1044.

Merle, U., Fein, E., Gehrke, S. G., Stremmel, W., Kulaksiz, H., 2007. The Iron Regulatory Peptide Hepcidin Is Expressed in the Heart and Regulated by Hypoxia and Inflammation. Endocrinology. 148, 2663-2668.

Miller, J. E., Horohov, D. W., 2006. Immunological aspects of nematode parasite control in sheep. J. Anim. Sci. 84, E124-E132.

Moncada, D. M., Kammanadiminti, S. J., Chadee, K., 2003. Mucin and Toll-like receptors in host defense against intestinal parasites. Trends Parasitol. 19, 305-311.

Nakayama, K., 1997. Furin: a mammalian subtilisin/Kex2p-like endoprotease involved in processing of a wide variety of precursor proteins. Biochem. $\mathrm{J}$. $327,625-635$.

Neils, J. S., Joshua, R. A., Oladusu, L. A., 2006. Response of microminerals in serum of sheep infected with Trypanosoma congolense. Afr. J. Biotechnol. 13, 1259-1262.

Nemeth, E., Valore, E.V., Territo, M., Schiller, G., Lichtenstein, A., Ganz, T., 2003. Hepcidin, a putative mediator of anemia of inflammation, is a type II acute-phase protein. Blood. 101, 2461-2463.

Nemeth, E.; Rivera, S.; Gabayan, V.; Keller, C.; Taudorf, S.; Pedersen, B.K.; Ganz, T., 2004a. IL-6 mediates hypoferremia of inflammation by inducing the synthesis of the iron regulatory hormone hepcidin. J. Clin. Invest. 113, 12711276.

Nemeth, E., Tuttle, M.S., Powelson, J., Vaughn, M.B., Donovan, A., Ward, D.M., Ganz, T., Kaplan, J., 2004b. Hepcidin regulates cellular iron efflux by binding to Ferroportin and inducing its internalization. Science. 306, 20902093. 
Nicolas, G., Chauvet, C., Viatte, L., Dana, J.L., Bigard, X., Devaux, I., Beaumont, C., Kahn, A., Vaulont, S., 2002. The gene encoding the iron regulatory peptide hepcidin is regulated by anemia, hypoxia, and inflammation. J. Clin. Invest. 110, 1037-1044.

Nielsen, H., Engelbrecht, J., Brunak, S., Von Heijne, G., 1997. Identification of prokaryotic and eukaryotic signal peptides and prediction of their cleavage sites. Protein. Eng. 10, 1-6.

Oliveira Filho, J.P., Badial, P.R., Cunha, P.H.J., Cruz, T.F., Araújo Jr, J.P., Divers, T.J., Winand, N.J., Borges, A.S., 2009. Cloning, sequencing and expression analysis of the equine hepcidin gene by real-time PCR. Vet. Immunol. Immunopathol. doi:10.1016/j.vetimm.2009.10.027

Ong, S.T., Ho. J.Z.S., Ho, B., Dinga, J.L., 2006. Iron-withholding strategy in innate immunity. Immunobiology. 211, 295-314.

Park, C.H., Valore, E.V., Waring, A.J., Ganz, T., 2001. Hepcidin, a Urinary Antimicrobial Peptide Synthesized in the Liver. J. Biol. Chem. 276, 7806-7810.

Pigeon, C., Ilyin, G., Courselaud, B., Leroyer, P., Turlin, B., Brissot, P., Loréal, O., 2001. A new mouse liver-specific gene, enconding a protein homologous to human antimicrobial peptide hepcidin, is overexpressed during iron overload. J. Biol. Chem. 276, 7811-7819.

Radtke, A.L., O'Riordan, M.X.D., 2006. Intracellular innate resistance to bacterial pathogens. Cell. Microbiol. 8, 1720-1729.

Roetto, A., Camaschella, C., 2005. New insights into iron homeostasis through the study of non-HFE hereditary haemochromatosis. Best. Pract. Res. Clin. Haematol. 18, 235-250.

Rossi, E., 2005. Hepcidin - the iron regulatory hormone. Clin. Biochem. Rev. 26, 47-49.

Saitou, N., Nei, M., 1987. The neighbor-joining method: A new method for reconstructing phylogenetic trees. Mol. Biol. Evol. 4, 406-425.

Sang, Y., Ramanathan, B., Minton, J.E., Ross, C.R., Blecha, F., 2006. Porcine liver-expressed antimicrobial peptides, hepcidin and LEAP-2: cloning and induction by bacterial infection. Dev. Comp. Immunol. 30, 357-366.

SAS Institute Inc., 2008. SAS/STAT 9. 2 User's Guide. SAS Institute Inc., Cary, N.C. 
Segat, L., Pontillo, A., Milanese, M., Tossi, A., Crovella, S., 2008. Evolution of the hepcidin gene in primates. BMC Genomics 9, 120.

Shike, H., Smimizu, C., Lauth, X., Burns, J.C., 2004. Organization and expression of the zebrafish hepcidina gene, an antimicrobial peptide gene conserved among vertebrates. Dev. Comp. Immunol. 28, 747-754.

Steiner, D. F., 1998. The proprotein convertases. Curr. Opin. Chem. Biol. 2, 3139.

Stockham SL, Scott MA., 2002. Fundamentals of Veterinary Clinical Pathology. 1th ed. Ames, IA: lowa State Press, 251-276.

Tamura, K., Dudley, J., Nei, M., Kumar, S., 2007. MEGA4: Molecular Evolutionary Genetics Analysis (MEGA) software version 4.0. Mol. Biol. Evol. 24, 1596-1599.

Taylor, K., McCullough, B., Clarke, D. J., Langley, R. J., Pechenick, T., Hill, A., Campopiano, D.J., Barran, P. E., Dorin, J. R., Govan, J. R. W., 2007. Covalent dimer species of ß-defensin defr1 display potent antimicrobial activity against multidrug-resistant bacterial pathogens. Antimicrob. Agents Chemother. 51, 1719-1724.

Van Merris, V., Meyer, E., Gasthuys, F., Burvenich, C., 2001. Sternal aspiration of bone in adult cows. Vlaams Diergeneeskundig Tijdschrift.70, 304-306.

Valore, E.V., Ganz, T., 2008. Posttranslational processing of hepcidin in human hepatocytes is mediated by the prohormone convertase furin. Blood Cells Mol. Dis. $40,132-138$.

Viatte, L., Vaulont, S., 2009. Hepcidin, the iron watcher. Biochimie. 91, 12231228.

Wang, K.J., Cai, J.J., Cai, L., Qu, H.D., Yang, M., Zhang, M., 2009. Cloning and expression of a hepcidin gene from a marine fish (Pseudosciaena crocea) and the antimicrobial activity of its synthetic peptide. Peptides. 30, 638-46.

Wise, R.J., Barr, P.J., Wong, P.A., Kiefer, M.C., Brake, A.J., Kaufman, R.J., 1990. Expression of a human proprotein processing enzyme: Correct cleavage of the von Willebrand factor precursor at a paired basic amino acid site. Proc. Natl. Acad. Sci. 87, 9378-9382.

Zechel, S., Huber-Wittmer, K., Halbach, O.B., 2006. Distribution of the ironregulating protein hepcidin in the murine central nervous system. J. Neurosci. Res. 84, 790-800. 
Zhang, Y.A., Zou, J., Chang, C.I., Secombes, C.J., 2004. Discovery and characterization of two types of liver-expressed antimicrobial peptide 2 (LEAP2) genes in rainbow trout. Vet. Immunol. Immunopathol. 101, 259-269. 
Table 1. Nucleotide sequences of primers used for specific gene amplification and for quantitative real-time PCR studies of sheep hepcidin.

\begin{tabular}{ccc}
\hline PRIMERS NAME & PRIMER SEQUENCE (5' to 3') & USE \\
\hline HEPC Forward 1 & TCCAGAGCAGGTCCTAGACCTAACG & cDNA \\
HEPC Reverse 1 & AAACAGGAGCTAGAACCAGACT & cDNA \\
Hepcidin Forward 2 & CACGACAGCTCACAGACCTC & q-PCR \\
Hepcidin Reverse 2 & AGATGCAGATGGGAAAGTGG & q-PCR \\
B-actin Forward & AGATGTGGATCAGCAAGCAGGAGT & q-PCR \\
B-actin Reverse & AGCTAACAGTCCGCCTAGAAGCAT & q-PCR \\
\hline
\end{tabular}




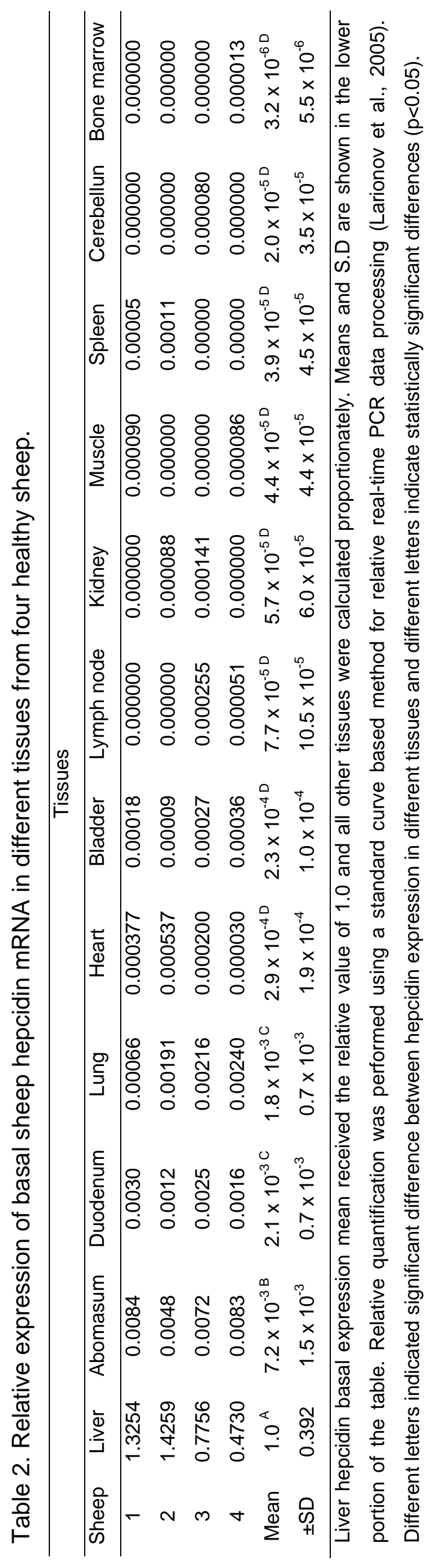




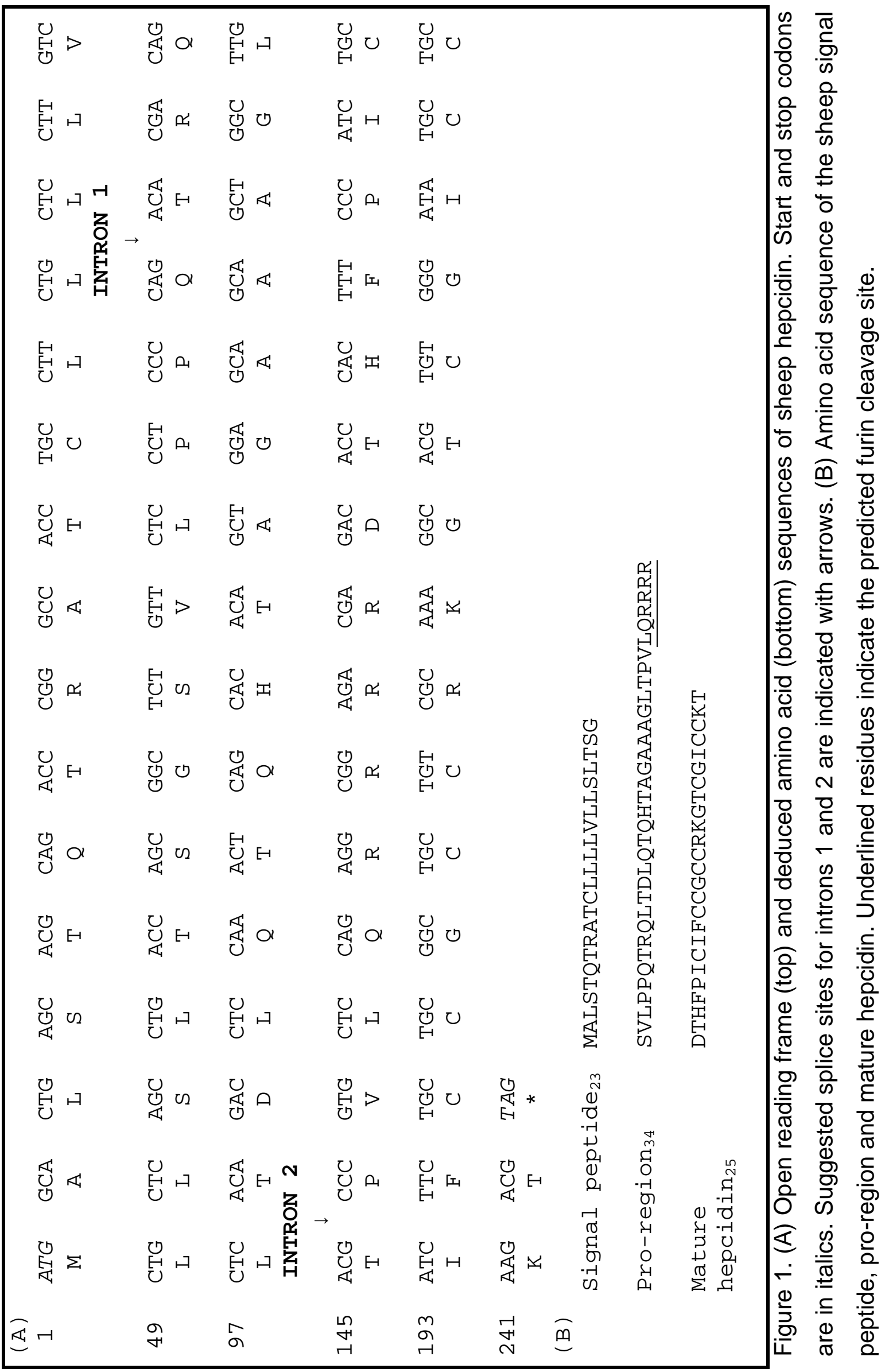




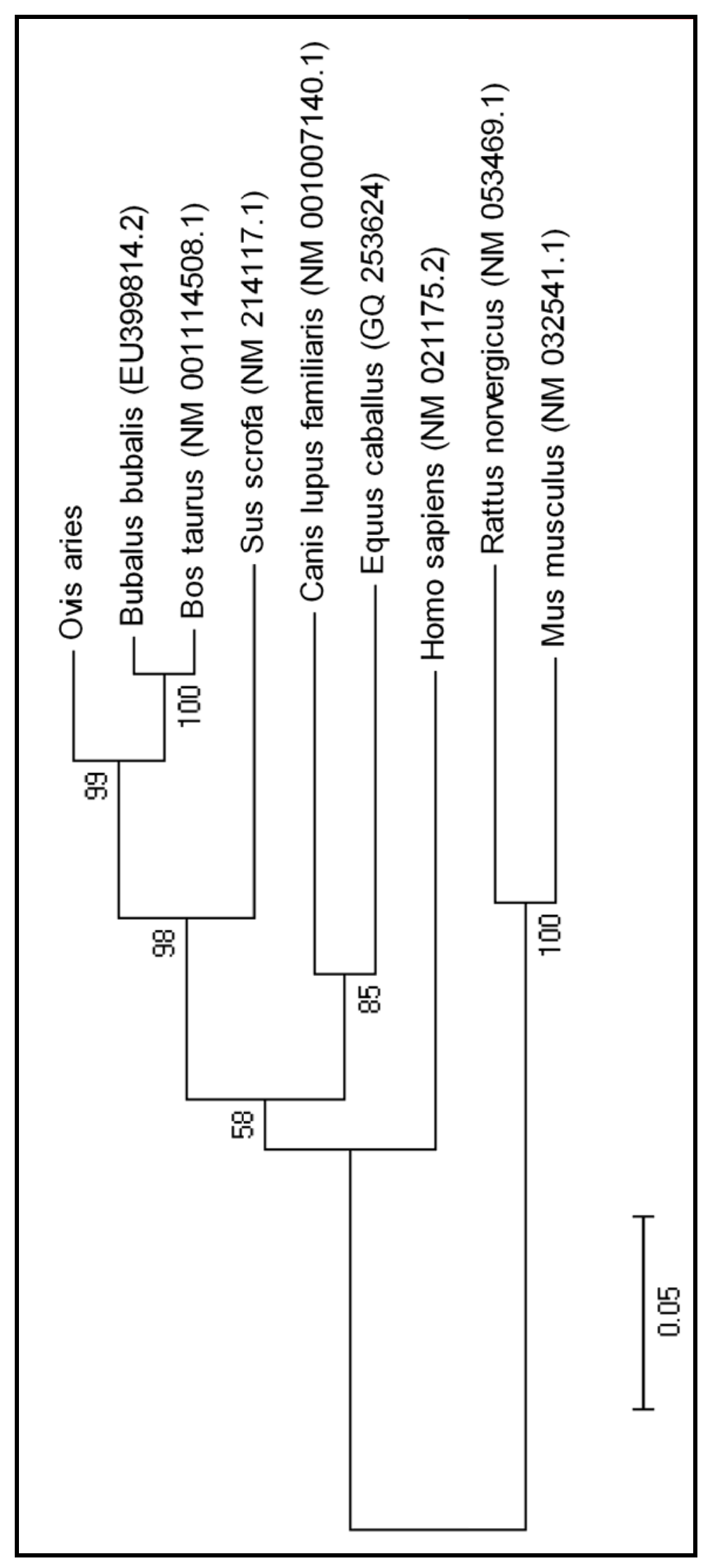

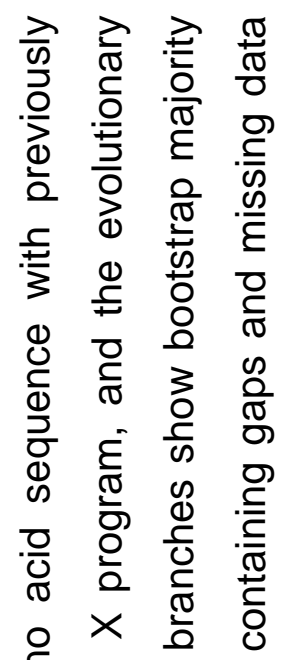

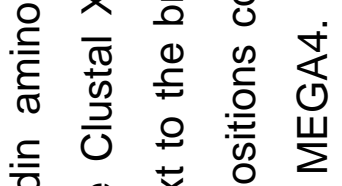

흥 巳 $\stackrel{\square}{\varrho} \cong$

只

웜 产 峁

ज

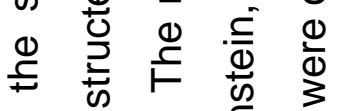

¿ ठ ठ்

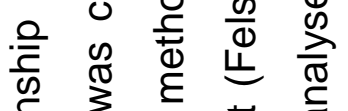

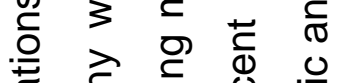

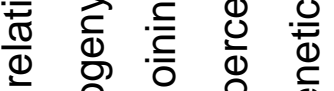

๑ 들

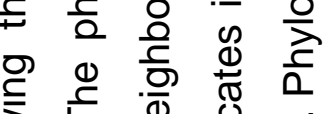

高 $\bar{i}$ 定

ज ญ 仓 巳

ه

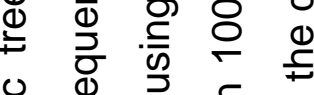

.

穴

i ᄃ

$\sim$ ठ

产竞 


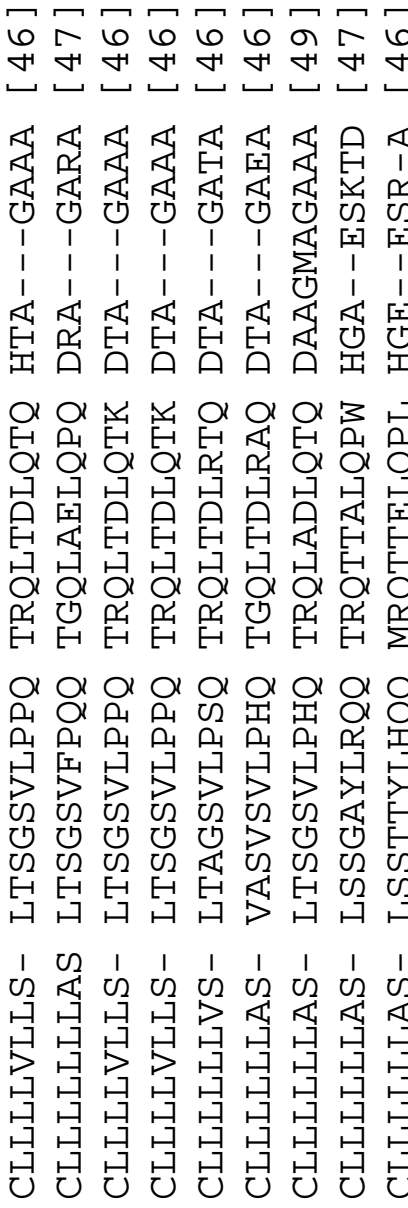

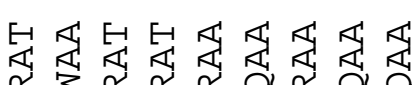

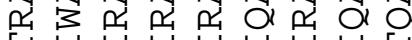

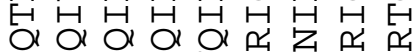

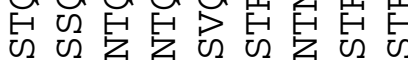
政

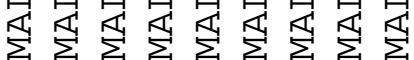

工े 붕 응 $\mapsto$

do

จேேロロேேロ $\infty \infty \infty \infty \infty \infty$

レレヒレヒレヒヒレ U U ৩ $\cup \cup \cup \cup \cup \cup \cup$

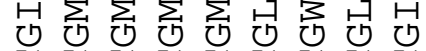

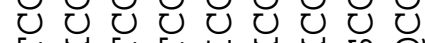

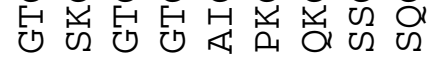

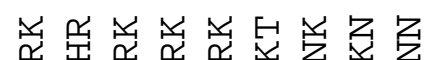
ن 엉 ن ن ن ن ن ن ن ن 늡 는 번법버법

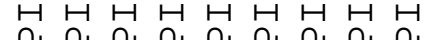

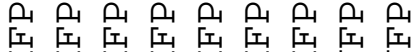

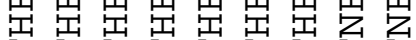

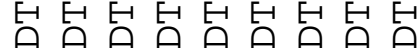

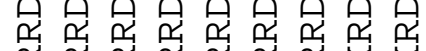

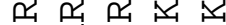
1

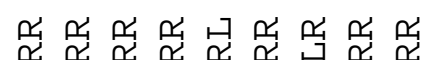

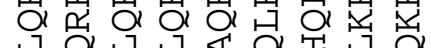

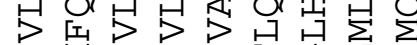
1' $\sum_{0}^{1} 11^{1}$

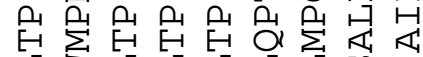

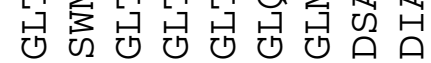
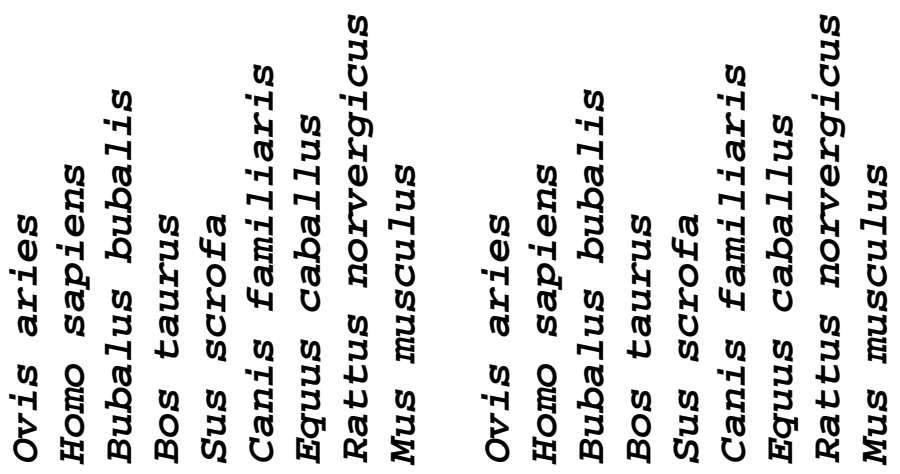


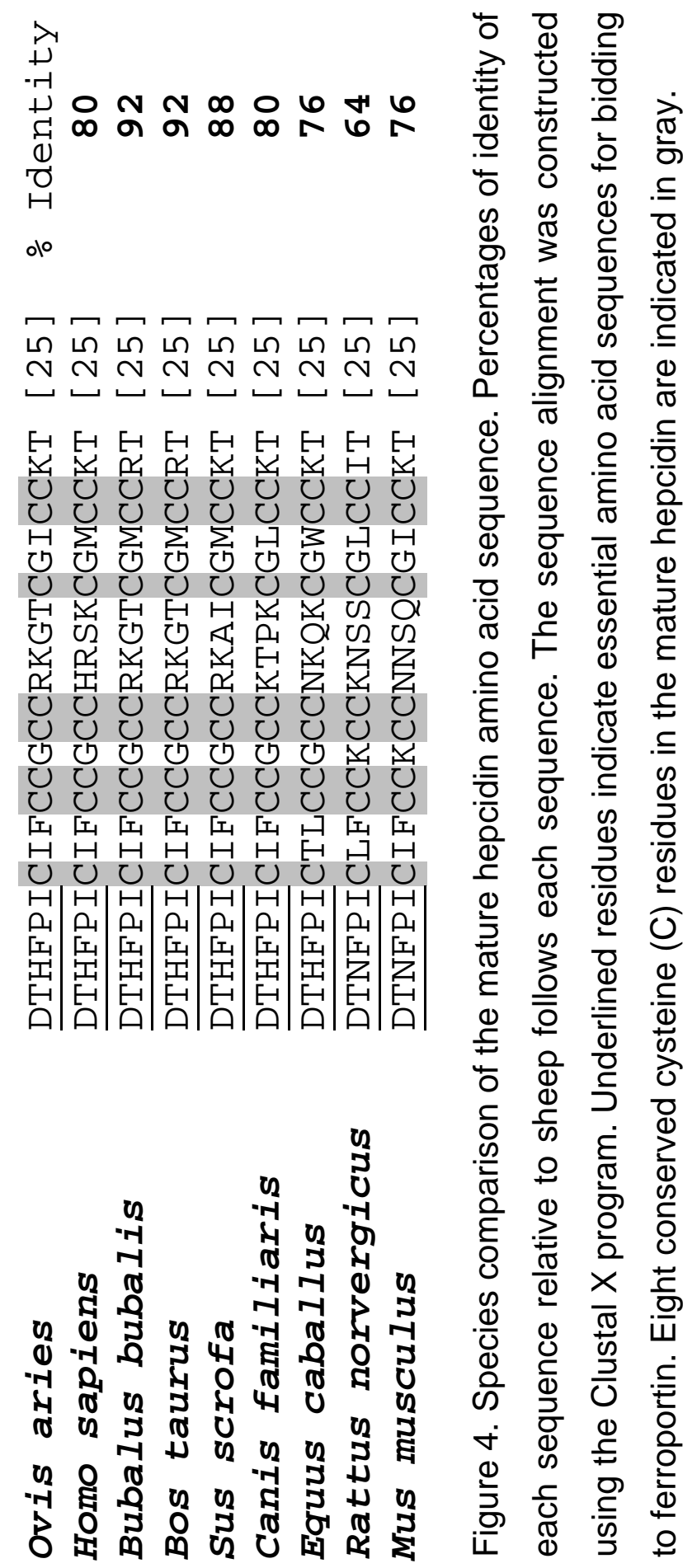


CAPÍTULO III 
CONCLUSÕES 


\section{CONCLUSÕES}

No presente estudo foi possível sequenciar o RNAm codificante (GenBankTM accession GQ901053), caracterizar e realizar a análise da expressão gênica da hepcidina em diferentes tecidos de ovinos hígidos.

A hepcidina foi predominantemente expressa no fígado. Níveis elevados de expressão também foram observados em outros tecidos, principalmente no abomaso. Este achado sugere uma possível ação local da hepcidina no abomaso, atuando como peptídeo antimicrobiano e/ou no metabolismo do ferro, sendo parte importante da imunidade inata deste tecido.

Este é o primeiro trabalho a descrever a sequência e o padrão de expressão gênica da hepcidina em ovinos clinicamente saudáveis e poderá auxiliar futuros estudos envolvendo inflamação e homeostase do ferro em ovinos. 
REFERENCIAS BIBLIOGRÁFICAS 


\section{REFERÊNCIAS BIBLIOGRÁFICAS}

Ahmad, K.A.; Ahmann, J.R.; Migas, M.C.; Waheed, A.; Britton, R.S.; Bacon, B.R.; Sly, W.S.; Fleming, R.E. Decreased liver hepcidin expression in the HFE knockout mouse. Blood Cells, Molecules, and Diseases, v.29, n.3, p.361-366, 2002.

Anderson, G.J.; Frazer, D.M.; Wilkins, S.J.; Becker, E.M.; Millard, K.N.; Murphy, T.L.; McKie, A.T.; Vulpe, C.D. Relationship between intestinal iron-transporter expression, hepatic hepcidin levels and the control of iron absorption. Biochemical Society Transactions, v.30, n.4, p.724-726, 2002.

Anderson, G.J.; Darshan, D.; Wilkins, S.J.; Frazer, D.M. Regulation of systemic iron homeostasis: how the body responds to changes in iron demand. Biometals, v.20, p.665-674, 2007.

Andrews, N.C. Disorders of iron metabolism. The New England Journal of Medicine, v.341, n.26, p.1986-1995, 1999.

Anualpec - Anuário da Pecuária Brasileira. 1 ed. São Paulo. Instituto FNP. 2006. 332p.

Atanasiu, V.; Manolescu, B.; Stoian, I. Hepcidin - central regulator of iron metabolism. European Journal of Haematology, v.78, p.1-10, 2006.

Babitt, J.L.; Huang, F.W.; Wrighting, D.M.; Xia, Y.; Sidis, Y.; Samad, T.A.; Campagna, J.A.; Chung, R.T.; Schneyer, A.L.; Woolf, C.J.; Andrews, N.C.; Lin, H.Y. Bone morphogenetic protein signaling by hemojuvelin regulates hepcidin expression. Nature Genetics, v.38, n.5, p.531-539, 2006.

Babitt, J.L.; Huang, F.W.; Xia, Y.; Sidis, Y.; Andrews, N.C.; Lin, H.Y. Modulation of bone morphogenetic protein signaling in vivo regulates systemic iron balance. The Journal of Clinical Investigation, v.117, n.7, p.1933-1939, 2007.

Borges, A.S.; Divers, T.J.; Stokol, T. Mohammed, O.H. Serum Iron and Plasma Fibrinogen Concentrations as Indicators of Systemic Inflammatory Diseases in Horses. Journal of Veterinary Internal Medicine, v.21, n.3, p.489-494, 2007. 
Braliou, G.G.; Falzacappa, M.V.V.; Chachami, G.; Casanovas, G.; Muckenthaler, M.U.; Simos, G. 2-Oxoglutarate-dependent oxygenases control hepcidin gene expression. Journal of Hepatology, v.48, p.801-810, 2008.

Bridle, K.R.; Frazer, D.M.; Wilkins, S.J.; Dixon, J.L.; Purdie, D.M.; Crawford, D.H.G.; Subramaniam, V.N.; Powell, L.W.; Anderson, G.J.; Ramm, G.A. Disrupted hepcidin regulation in HFE-associated haemochromatosis and the liver as a regulator of body iron homoeostasis. The Lancet, v.361, p.669-673, 2003.

Chen, S.L.; Xu, M.Y.; Ji, X.S.; Yu, G.C.; Liu, Y. Cloning, Characterization, and Expression Analysis of Hepcidin Gene from Red Sea Bream (Chrysophrys major). Antimicrobial Agents and Chemotherapy, v.49, p.1608-1612, 2005.

Collins, J.F.; Wessling-Resnick, M.; Knutson, M.D. Hepcidin regulation of iron transport. The Journal of Nutrition, v.138, p. 2284-2288, 2008.

Constante, M.; Jiang, W.; Wang, D.; Raymond, V.; Bilodeau, M.; Santos, M.M. Distinct requirements for $\mathrm{Hfe}$ in basal and induced hepcidin levels in iron overload and inflammation. American Journal of Physiology - Gastrointestinal and Liver Physiology, v.291, p.229-237, 2006.

Courselaud, B. ; Pigeon, C.; Inoue, Y. ; Inoue, J. ; Gonzalez, F.J. ; Leroyer, P.; Gilot, D.; Boudjema, K.; Guguen-Guillouzo, C.; Brissot, P.; Loréal, O.; llyin, G. C/EBPa regulates hepatic transcription of hepcidin, an antimicrobial peptide and regulator of iron metabolism. The Journal of Biological Chemistry, v.277, n.43, p.41163-41170, 2002.

Cunietti, E.; Chiari, M.M.; Monti, M.; Engaddi, I.; Berlusconi, A.; Neri, M.C.; De Luca, P. Distortion of iron status indices by acute inflammation in older hospitalized patients. Archives of Gerontology and Geriatrics, v.39, n.1, p.3542, 2004.

Darshan, D.; Anderson, G.J. Interacting signals in the control of hepcidin expression. Biometals, v.22, p.77-87, 2009.

De Domenico, I.; Ward, D.M.; Kaplan, J. Hepcidin regulation: ironing out the details. The Journal of Clinical Investigation, v.117, n.7, p.1755-1758, 2007. 
De Domenico, I.; Nemeth, E.; Nelson, J.M.; Phillips, J.D.; Ajioka, R.S.; Kay, M.S.; Kushner, J.P.; Ganz, T.; Ward, D.M.; Kaplan, J. The hepcidin-binding site on ferroportin is evolutionarily conserved. Cell Metabolism, v.8, p.146156, 2008.

Douglas, S.E.; Gallant, J.W.; Liebscher, R.S.; Dacanay, A.; Tsoi, S.C.M. Identification and expression analysis of hepcidin-like antimicrobial peptides in bony fish. Developmental \& Comparative Immunology, v.27, p.589-601, 2003.

Dunn, L.L.; Rahmanto, Y.S.; Richardson, D.R. Iron uptake and metabolism in the new millennium. Trends in Cell Biology, v.17, n.2, p.93-100, 2007.

Erskine, R.J.; Bartlett, P.C. Serum concentrations of copper, iron and zinc during Escherichia coli-induced mastitis. Journal of Dairy Science, v.76, n.2, p.408-413, 1993.

Falzacappa, M.V.V.; Muckenthaler, M.U. Hepcidin: Iron-hormone and antimicrobial peptide. Gene, v.364, p.37-44, 2005.

Feder, J.N.; Penny, D.M.; Irrinki, A.; Lee, V.K.; Lebrón, J.A.; Watson, N.; Tsuchihashi, Z.; Sigal, E.; Bjorkman, P.J.; Schatzman, R.C. The hemochromatosis gene product complexes with the transferrin receptor and lowers its affinity for ligand binding. Proceedings of the National Academy of Sciences, v.95, p.1472-1477, 1998.

Feldman, B.F.; Kaneko, J.J.; Farver, T.B. The anemia of inflammatory disease in the dog. I. The nature of the problem. Veterinary Research Communications, v.4, n.4, p.237-252, 1981.

Fleming, M.D. The regulation of hepcidin and its effects on systemic and cellular iron metabolism. Hematology, p.151-158, 2008.

Frazer, D.M.; Wilkins, S.J.; Becker, E.M.; Vulpe, C.D.; Mckie, A.T.; Trinder, D.; Anderson, G.J. Hepcidin expression inversely correlates with the expression of duodenal iron transporters and iron absorption in rats. Gastroenterology, v.123, p.835-844, 2002. 
Frazer, D.M.; Anderson, G.J. The orchestration of body iron intake: how and where do enterocytes receive their cues?. Blood Cells, Molecules, and Diseases, v.30, p.288-297, 2003.

Frazer, D.M.; Inglis, H.R.; Wilkins, S.J.; Millard, K.N.; Steele, T.M.; McLaren, G.D.; McKie, A.T.; Vulpe, C.D.; Anderson, G.J. Delayed hepcidin response explains the lag period in iron absorption following a stimulus to increase erythropoiesis. Gut, v.53, p.1509-1515, 2004.

Frazer, D.M.; Wilkins, S.J.; Millard, K.N.; McKie, A.T.; Vulpe, C.D.; Anderson, G.J. Increased hepcidin expression and hypoferraemia associated with an acute phase response are not affected by inactivation of HFE. British Journal of Haematology, v.126, p.434-436, 2004a.

Fry, M.M.; Liggett, J.L.; Baek, S.J. Molecular cloning and expression of canine hepcidin. Veterinary Clinical Pathology, v.33, p.223-227, 2004.

Fu, Y.M.; Li, S.P.; Wu, Y.F.; Chang, Y.G. Identification and expression analysis of hepcidin-like cDNAs from pigeon (Columba livia). Molecular and Cellular Biochemistry, v.305, p.191-197, 2007.

Ganz, T. Hepcidin, a key regulator of iron metabolism and mediator of anemia of inflammation. Blood, v.102, p.783-788, 2003.

Ganz, T. Hepcidin in iron metabolism. Current Opinion in Hematology, v.11, n.4, p.251-254, 2004.

Ganz, T. Hepcidin - a regulator of intestinal iron absorption and iron recycling by macrophages. Best practice \& research clinical haematology, v.18, n.2, p.171-182, 2005.

Ganz, T. Hepcidin and its role in regulating systemic iron metabolism. Hematology, p.29-35, 2006.

Ganz, T.; Nemeth, E. Iron imports IV. Hepcidin and regulation of body iron metabolism. American journal of physiology - gastrointestinal and liver physiology, v.290, 199-203, 2006. 
Ganz, T. Molecular Control of Iron Transport. Journal of the American Society of Nephrology, v.18, p.394-400, 2007.

Gao, J.; Chen, J.; Kramer, M.; Tsukamoto, H.; Zhang, A.; Enns, C.A. Interaction of hereditary hemochromatosis protein HFE with transferrin receptor 2 is required for transferrin-induced hepcidin expression. Cell Metabolism, v.9, n.3, p.217-227, 2009.

Heinrich, P.C.; Behrmann, I.; Haan, S.; Hermanns, H.M.; Müller-Newen, G.; Schaper, F. Principles of interleukin (IL)-6-type cytokine signalling and its regulation. Biochemical Journal, v.374, p.1-20, 2003.

Hershko, C.; Cook, J.D.; Finch, C.A. Storage iron kinetics. VI. The effect of inflammation on iron exchange in the rat. British Journal of Haematology, v.28, p.67-75, 1974.

Hilton, K.B.; Lambert, L.A. Molecular evolution and characterization of hepcidin gene products in vertebrates. Gene, v.415, p.40-48, 2008.

Huang, H.; Constante, M.; Layoun, A.; Santos, M.M. Contribution of STAT3 and SMAD4 pathways to the regulation of hepcidin by opposing stimuli. Blood, v.113, n.15, p.3593-3599, 2009.

Hulten, C.; Gronlund, U.; Hirvonen, J.; Tulamo, R.M; Suominen, M.M.; Marhauq, G.; Forsberg, M. Dynamics in serum of the inflammatory markers serum amyloid A (SAA), haptoglobin, fibrinogen and alpha2-globulins during induced noninfectious arthritis in the horse. Equine Veterinary Journal, v.34, n.7, p.699-704, 2002.

Hunter, H.N.; Fulton, D.B.; Ganz, T.; Vogel, H.J. The Solution Structure of Human Hepcidin, a Peptide Hormone with Antimicrobial Activity That Is Involved in Iron Uptake and Hereditary Hemochromatosis. The journal of biological chemistry, v.277, n.40, p.37597-37603, 2002.

Ilyin, G.; Courselaud, B.; Troadec, M.B.; Pigeon, C.; Alizadeh, M.; Leroyer, P.; Brissot, P.; Loréal, O. Comparative analysis of mouse hepcidin 1 and 2 genes: evidence for different patterns of expression and co-inducibility during iron overload. Febs Letters, v.542, p.22-26, 2003. 
Jones, M.L.; Allisson, R.W. Evaluation of the ruminant complete blood cell count. Veterinary Clinics of North America: Food Animal Practice, v.23, p.377402, 2007.

Kanda, J.; Mizumoto, C.; Kawabata, H.; Tsuchida, H.; Tomosugi, N.; Matsuo, K.; Uchiyama, T. Serum hepcidin level and erythropoietic activity after hematopoietic stem cell transplantation. Haematologica, v.93, n.10, p.15501554, 2008.

Kawabata, H.; Germain, R.S.; Vuong, P.T.; Nakamaki, T.; Saidi, J.W.; Koeffler, H.P. Transferrin receptor 2- $\alpha$ supports cell growth both in iron-chelated cultured cells and in vivo. The Journal of Biological Chemistry, v.275, n.22, p.16618-16625, 2000.

Kawabata, H.; Germain, R.S.; Ikezoe, T.; Tong, X.; Green, E.M.; Gombart, A.F.; Koeffler, H.P. Regulation of expression of murine transferrin receptor 2. Blood, v.98, n.6, p.1949-1954, 2001.

Kawabata, H.; Fleming, R.E.; Gui, D.; Moon, S.Y.; Saitoh, T.; O’Kelly, J.; Umehara, Y.; Wano, Y.; Said, J.W.; Koeffler H.P. Expression of hepcidin is down-regulated in TfR2 mutant mice manifesting a phenotype of hereditary hemochromatosis. Blood, v.105, n.1, p.376-381, 2005.

Kemna, E.; Pickkers, P.; Nemeth, E.; Hoeven, H.; Swinkels, D. Time-course analysis of hepcidin, serum iron, and plasma cytokine levels in humans injected with LPS. Blood, v.106, n.5, p.1864-1866, 2005.

Krause, A.; Neitz, S.; Mägert, H.; Schulz, A.; Forssmann, W.; Schulz-Knappe, P.; Adermann, K. LEAP-1, a novel highly disulfide-bonded human peptide, exhibits antimicrobial activity. Federation of European Biochemical Societies, v.480, p.147-150, 2000.

Kulaksiz, H.; Theilig, F.; Bachmann, S.; Gehrke, S.G.; Rost, D.; Janetzko, A.; Cetin, Y.; Stremmel, W. The iron-regulatory peptide hormone hepcidin: expression and cellular localization in the mammalian kidney. Journal of Endocrinology, v.184, p.361-370, 2005. 
Kulaksiz, H.; Fein, E.; Redecker, P.; Stremmel, W.; Adler, G.; Cetin, Y. Pancreatic $\beta$-cells express hepcidin, an iron-uptake regulatory peptide. Journal of endocrinology, v.197, p.241-249, 2008.

Lauth, X.; Babon, J.J.; Stannard, J. A.; Singh, S.; Nizet, V.; Carlberg, J.M.; Ostland, V.E.; Pennington, M.W.; Norton, R.S.; Westerman, M.E. Bass hepcidin synthesis, solution structure, antimicrobial activities and synergism, and in vivo hepatic response to bacterial infections. The Journal of Biological Chemistry, v.280, p.9272-9282, 2005.

Lee, P.; Peng, H.; Gelbart, T.; Beutler, E. The IL-6- and lipopolysaccharideinduced transcription of hepcidin in HFE-, transferrin receptor 2-, and ß2microglobulin-deficient hepatocytes. Proceedings of the National Academy of Sciences, v.101, n.25, p.9263-9265, 2004.

Lee, P.; Peng, H.; Gelbart, T,. Wang, L.; Beutler, E. Regulation of hepcidin transcription by interleukin-1 and interleukin-6. Proceedings of the National Academy of Sciences, v.102, n.6, p.1906-1910, 2005.

Leibman, A.; Aisen, P. Distribution of iron between the binding sites of transferrin in serum: methods and results in normal human subjects. Blood, v.53, n.6, p.1058-1065, 1979.

Leong, W.; Lönnerdal, B. Hepcidin, the recently identified peptide that appears to regulate iron absorption. The journal of nutrition, v.134, p.1-4, 2004.

Lin, L.; Goldberg, Y.P.; Ganz, T. Competitive regulation of hepcidin mRNA by soluble and cell-associated hemojuvelin. Blood, v.106, n.8, p.2884-2889, 2005.

Lin, L.; Valore, E.V.; Nemeth, E.; Goodnough, J.B.; Gabayan, V.; Ganz, T. Iron transferrin regulates hepcidin synthesis in primary hepatocyte culture through hemojuvelin and BMP2/4. Blood, v.110, n.6, p.2182-2189, 2007.

Liu, X; Nguyen, N.H.; Marquess, K.D.; Yang, F.; Haile, D.J. Regulation of hepcidin and ferroportin expression by lipopolysaccharide in splenic macrophages. Blood cells, molecules, and diseases, v.35, p.47-56, 2005. 
Mattioli, A.V.; Bonetti, L.; Zennaro, M.; Ripa, S.; Mattioli, G. Prognostic value of iron, nutritional status indexes and acute phase protein in acute coronary syndromes. Italian Heart Journal, v.3, n.3, p.194-198, 2002.

Merle, U.; Fein, E.; Gehrke, S.G.; Stremmel, W.; Kulaksiz, H. The iron regulatory peptide hepcidin is expressed in the heart and regulated by hypoxia and inflammation. Endocrinology, v.148, n.6, p.2663-2668, 2007.

Nemeth, E.; Valore, E.V.; Territo, M.; Schiller, G.; Lichtenstein, A.; Ganz, T. Hepcidin, a putative mediator of anemia of inflammation, is a type II acutephase protein. Blood, v.101, n.7, p.2461-2463, 2003.

Nemeth, E.; Rivera, S.; Gabayan, V.; Keller, C.; Taudorf, S.; Pedersen, B.K.; Ganz, T. IL-6 mediates hypoferremia of inflammation by inducing the synthesis of the iron regulatory hormone hepcidin. The Journal of Clinical Investigation, v.113, n.9, p.1271-1276, $2004 a$.

Nemeth, E.; Tuttle, M.S.; Powelson, J.; Vaughn, M.B.; Donovan, A.; Ward, D.M.; Ganz, T.; Kaplan, J. Hepcidin regulates cellular iron efflux by binding to ferroportin and inducing its internalization. Science, v.306, p.2090-2093, 2004b.

Nemeth, E.; Roetto, A.; Garozzo, G.; Ganz, T.; Camaschella, C. Hepcidin is decreased in TFR2 hemochromatosis. Lood, v.105, n. 4, p.1803-1806, 2005.

Nemeth, E.; Preza, G.C.; Jung, C.; Kaplan, J.; Waring, A.J.; Ganz, T. The Nterminus of hepcidin is essential for its interaction with ferroportin: structurefunction study. Blood, v.107, n.1, p.328-333, 2006.

Nicolas, G.; Bennoun, M.; Devaux, I.; Beaumont, C.; Grandchamp, B.; Kahn, A.; Vaulont, S. Lack of hepcidin gene expression and severe tissue iron overload in upstream stimulatory factor 2 (USF2) knockout mice. Proceedings of the national academy of sciences, v.98, n.15, p.8780-8785, 2001.

Nicolas, G.; Chauvet, C.; Viatte, L.; Danan, J.L ; Bigard, X.; Devaux, I.; Beaumont, C.; Kahn, A.; Vaulont, S. The gene encoding the iron regulatory peptide hepcidin is regulated by anemia, hypoxia, and inflammation. The journal of clinical investigation, v.110, n.7, p.1037-1044, 2002a. 
Nicolas, G.; Bennoun, M.; Porteu, A.; Mativet, S.; Beaumont, C.; Grandchamp, B.; Sirito, M.; Sawadogo, M.; Kahn, A.; Vaulont, S. Severe iron deficiency anemia in transgenic mice expressing liver hepcidin. Proceedings of the National Academy of Sciences, v.99, n.7, p.4596-4601, 2002b.

Nicolas, G.; Viatte, L.; Bennoun, M.; Beaumont, C.; Kahn, A.; Vaulont, S. Hepcidin, a new iron regulatory peptide. Blood cells, Molecules, and diseases, v.29, n.3, p.327-335, 2002c.

Niederkofler, V.; Salie, R.; Arber, S. Hemojuvelin is essential for dietary iron sensing, and its mutation leads to severe iron overload. The Journal of Clinical Investigation, v.115, n.8, p.2180-2186, 2005.

Nielsen, B.H.; Jacobsen, S.; Andersen, P.H.; Niewold, T.A.; Heegaard, P.M.H. Acute phase protein concentrations in serum and milk from cows with clinical mastitis, with extramammary inflammatory conditions and clinically healthy cows. The Veterinary Record, v.154, n.12, p.1011-1016, 2004.

Oates, P.S.; Ahmed, U. Molecular regulation of hepatic expression of iron regulatory hormone hepcidin. Journal of Gastroenterology and Hepatology, v.22, p.1378-1387, 2007.

Oldekamp, J.; Krämer, N.; Alvarez-Bolado, G.; Skutella, T. Expression pattern of the repulsive guidance molecules RGM A, B and C during mouse development. Gene Expression Patterns, v.4, p.283-288, 2004.

Oliveira Filho, J.P.; Badial, P.R.; Cunha, P.H.J.; Cruz, T.F.; Araújo Jr, J.P.; Divers, T.J.; Winand, N.J.; Borges, A.S. Cloning, sequencing and expression analysis of the equine hepcidin gene by real-time PCR. Veterinary Immunology and Immunopathology. doi:10.1016/j.vetimm.2009.10.027.

Ortolani, E.L. Toxemia da prenhez nos pequenos ruminantes. Anais do II Simpósio de caprinos e ovinos da EV-UFMG. 2007. p.197-203.

Pak, M.; Lopez, M.A.; Gabayan, V.; Ganz, T.; Rivera, S. Suppression of hepcidin during anemia requires erythropoietic activity. Blood, v.108, p.37303735, 2006. 
Papanikolaou, G.; Samuels, M.E.; Ludwig, E.H.; MacDonald, M.L.E.; Franchini, P.L.; Dubé, M.; Andres, L.; MacFarlane, J.; Sakellaropoulos, N.; Politou, M.; Nemeth, E.; Thompson, J.; Risler, J.K.; Zaborowska, C.; Babakaiff, R.; Radomski, C.C.; Pape, T.D.; Davidas, O.; Christakis, J.; Brissot, P.; Lockitch, G.; Ganz, T.; Hayden, M.R.; Goldberg, Y.P. Mutations in HFE2 cause iron overload in chromosome 1q-linked juvenile hemochromatosis. Nature Genetics, v.36, n.1, p.77-82, 2004.

Park, C.H.; Valore, E.V.; Waring, A.J.; Ganz, T. Hepcidin, a Urinary Antimicrobial Peptide Synthesized in the Liver. The journal of biological chemistry, v.276, n.11, p.7806-7810, 2001.

Petersen, H.H.; Nielsen, J.P., Heegaard, P.M. Application of acute phase protein measurements in veterinary clinical chemistry. Veterinary Research, v.35, n.2, p.163-87, 2004.

Peyssonnaux, C.; Zinkernagel, A.S.; Schuepbach, R.A.; Rankin, E.; Vaulont, S.; Haase, V.H.; Nizet, V.; Johnson, R.S. Regulation of iron homeostasis by the hypoxia-inducible transcription factors (HIFs). The Journal of Clinical Investigation, v.117, n.7, p.1926-1932, 2007.

Peyssonnaux, C.; Nizet, V; Johnson, R.S. Role of the hypoxia inducible factors in iron metabolism. Cell Cycle, v.7, n.1, p.28-32, 2008.

Pigeon, C.; Ilyin, G.; Courselaud, B.; Leroyer, P.; Turlin, B.; Brissot, P.; Loréal, O. A New Mouse Liver-specific Gene, Encoding a Protein Homologous to Human Antimicrobial Peptide Hepcidin, Is Overexpressed during Iron Overload. The journal of biological chemistry, v.276, n.11, p.7811-7819, 2001.

Pinto, J.P.; Ribeiro, S.; Pontes, H.; Thowfeequ, S.; Tosh, D.; Carvalho, F.; Porto, G. Erythropoietin mediates hepcidin expression in hepatocytes through EPOR signaling and regulation of C/EBPa. Blood, v.111, n.12, p.5725-5733, 2008.

Pugh, D.G. Sheep na goat medicine. 1 ed. Editora Roca: São Paulo. 2001. $468 p$. 
Radostits, O.M.; Mayhew, I.G.J.; Houston, D.M. Exame clínico e diagnóstico em veterinária. 1 ed. Rio de Janeiro: Guanabara-Koogan, 2002. 591p.

Radtke, A.L.; O'Riordan, M.X.D. Intracellular innate resistance to bacterial pathogens. Cellular Microbiology, v. 8, n.11, p.1720-1729, 2006.

Ramey, G.; Deschemin, J.; Vaulont, S. Cross-talk between the mitogen activated protein kinase and bone morphogenetic protein/hemojuvelin pathways is required for the induction of hepcidin by holotransferrin in primary mouse hepatocytes. Haematologica, v.94, p.765-772, 2009.

Roetto, A.; Totaro, A.; Piperno, A.; Piga, A.; Longo, F.; Garozzo, G.; Cali, A.; De Gobbi, M.; Gasparini, P.; Camaschella, C. New mutations inactivating transferrin receptor 2 in hemochromatosis type 3. Blood, v.97, n.9, p.25552560, 2001.

Santos, P.C.J.L.; Cançado, R.D.; Terada, C.T.; Guerra-Shinohara, E.M. Alterações moleculares associadas à hemocromatose hereditária. Revista Brasileira de Hematologia e Hemoterapia, v.31, n.3, p.192-202, 2009.

Sang, Y.; Ramanathan, B.; Minton, J.E.; Ross, C.R.; Blecha, F. Porcine liverexpressed antimicrobial peptides, hepcidin and LEAP-2: cloning and induction by bacterial infection. Developmental \&.Comparative Immunology, v.30, p.357-366, 2006.

Schalm, O.W.; Smith, R.; Kaneko, J.J. Plasma protein: fibrinogen rations in dogs, cattle and horses. Part I. Influence of age on normal values and explanation of use in disease. The California Veterinary, 1970.

Segat, L.; Pontillo, A.; Milanese, M.; Tossi, A.; Crovella, S. Evolution of the hepcidin gene in primates. BMC Genomics, v.9, p.120, 2008.

Shi, Y.; Massagué, J. Mechanisms of TGF- $\beta$ signaling from cell membrane to the nucleus. Cell, v.113, p.685-700, 2003.

Shike, H.; Smimizu, C.; Lauth, X.; Burns, J.C. Organization and expression of the zebrafish hepcidina gene, an antimicrobial peptide gene conserved among 
vertebrates. Developmental \&.Comparative Immunology, v.28, p.747-754, 2004.

Sow, F.B.; Florence, W.C.; Satoskar, A.R.; Schlesinger, L.S.; Zwilling, B.C.; Lafuse, W.P. Expression and localization of hepcidin in macrophages: a role in host defense against tuberculosis. Journal of leukocyte biology, v.82, p.934945, 2007.

Spasic, M.V.; Kiss, J.; Herrmann, T.; Galy, B.; Martinache, S.; Stolte, J.; Gröne, H.; Stremmel, W.; Hentze, M.W.; Muckenthaler, M.U. HFE acts in hepatocytes to prevent hemochromatosis. Cell Metabolism, v.7, p.173-178, 2008.

Tanno, T.; Bhanu, N.V.; Oneal, P.A.; Goh, S.; Staker, P.; Lee, Y.T.; Moroney, J.W.; Reed, C.H.; Luban, N.L.C.; Wang, R.; Eling, T.E.; Childs, R.; Ganz, T.; Leitman, S.F.; Fucharoen, S.; Miller, J.L. High levels of GDF15 in thalassemia suppress expression of the iron regulatory protein hepcidin. Nature Medicine, v.13, n.9, p.1096-1101, 2007.

Viatte, L.; Vaulont, S. Hepcidin, the iron watcher. Biochimie, v.91, p.1223-1228, 2009.

Vokurka, M.; Krijt, J.; Sulc, K.; Necas, E. Hepcidin mRNA levels in mouse liver respond to inhibition of erythropoiesis. Physiological Research, v.55, p.667674, 2006.

Vyoral, D.; Petrák, J. Hepcidin: a direct link between iron metabolism and immunity. The international journal of biochemistry \& cell biology, v.37, p.1768-1773, 2005.

Wang, R.; Li, C.; Xu, X.; Zheng, Y.; Xiao, C.; Zerfas, P.; Cooperman, S.; Eckhaus, M.; Rouault, T.; Mishra, L.; Deng, C. A role of SMAD4 in iron metabolism through the positive regulation of hepcidin expression. Cell Metabolism, v.2, p.399-409, 2005. 
Wang, Q.; Du, F.; Qian, Z.; Ge, X.H.; Zhu, L.; Yung, W.H.; Yang, L.; Ke, Y. Lipopolysaccharide induces a significant increase in expression of iron regulatory hormone hepcidin in the cortex and substantia nigra in rat brain. Endocrinology, v.149, n.8, p.3920-3925, 2008.

Wang, K.J.; Cai, J.J.; Cai, L.; Qu, H.D.; Yang, M.; Zhang, M. Cloning and expression of a hepcidin gene from a marine fish (Pseudosciaena crocea) and the antimicrobial activity of its synthetic peptide. Peptides, v.30, p.638-46, 2009.

Weinstein, D.A.; Roy, C.N.; Fleming, M.D.; Loda, M.F.; Wolfsdorf, J.I.; Andrews, N.C. Inappropriate expression of hepcidin is associated with iron refractory anemia: implications for the anemia of chronic disease. Blood, v.100, n.10, p.3776-3781, 2002.

Wrighting, D.M.; Andrews, N.C. Iron Homeostasis and Erythropoiesis. Current Topics in Developmental Biology, v.82, p.141-167, 2008.

Young, S.P.; Bomford, A.; Williams, R. The effect of the iron saturation of transferrin on its binding and uptake by rabbit reticulocytes. Biochemical. Journal, v.219, p.505-510, 1984.

Zhang, A.; Xiong, S.; Tsukamoto, H.; Enns, C.A. Localization of iron metabolism-related mRNAs in rat liver indicate that HFE is expressed predominantly in hepatocytes. Blood, v.103, n.4, p.1509-1514, 2004.

Zhao, G. Consequences of knocking out BMP signaling in the mouse. Genesis, v.35, p.43-56, 2003. 
ANEXOS 
TABELAS INDIVIDUAIS 


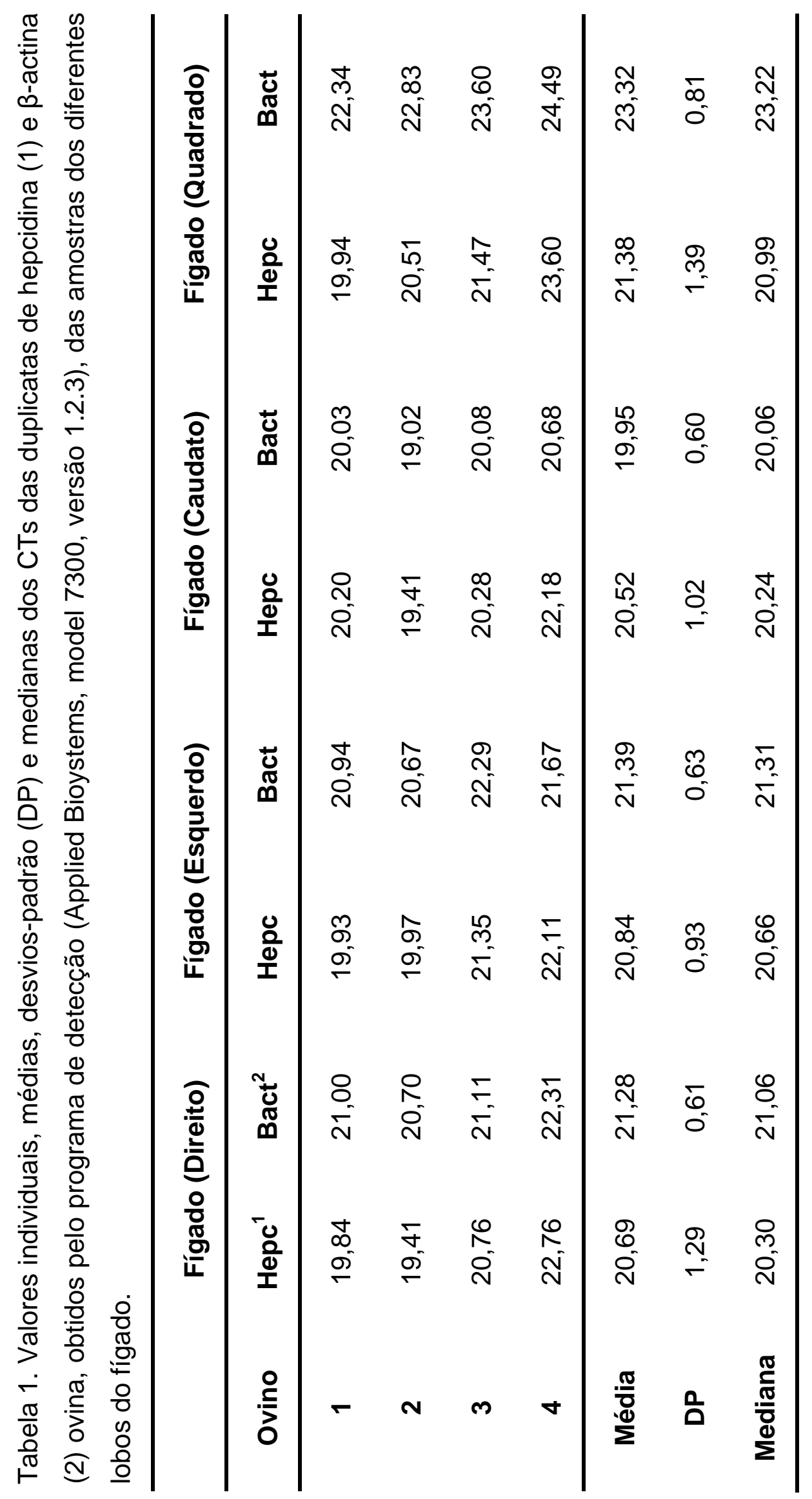




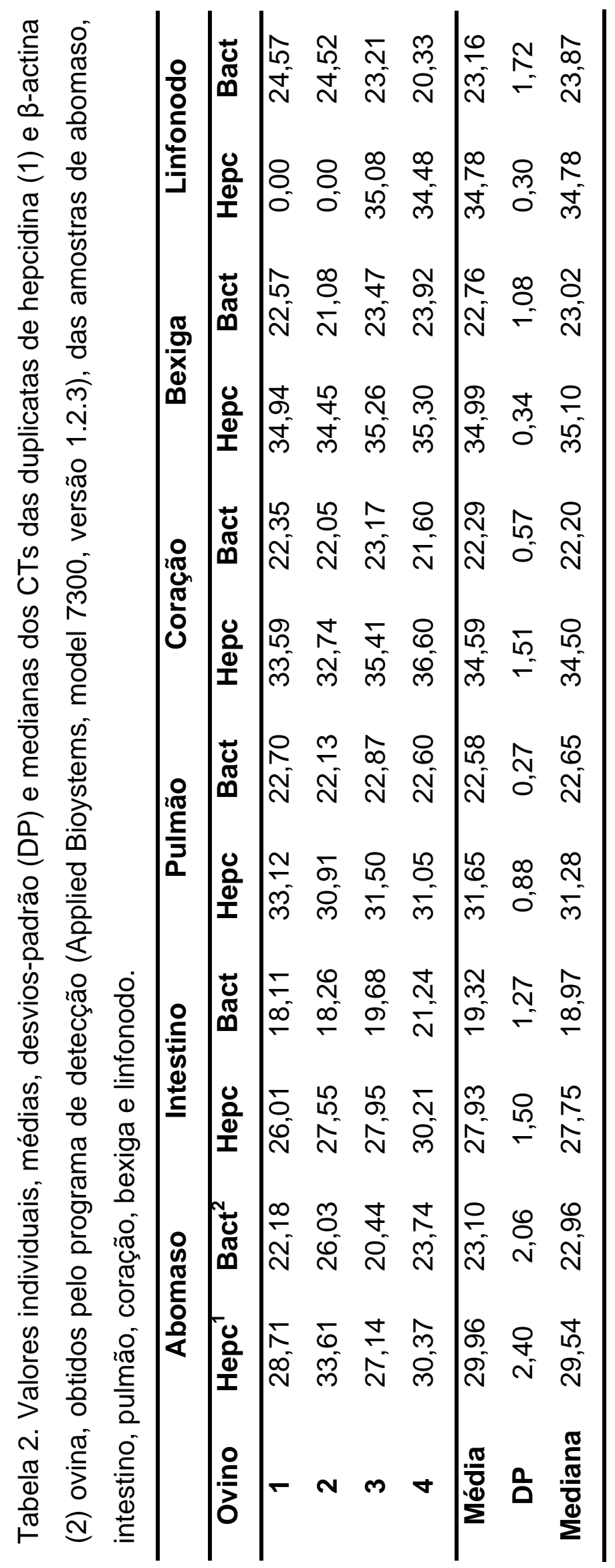




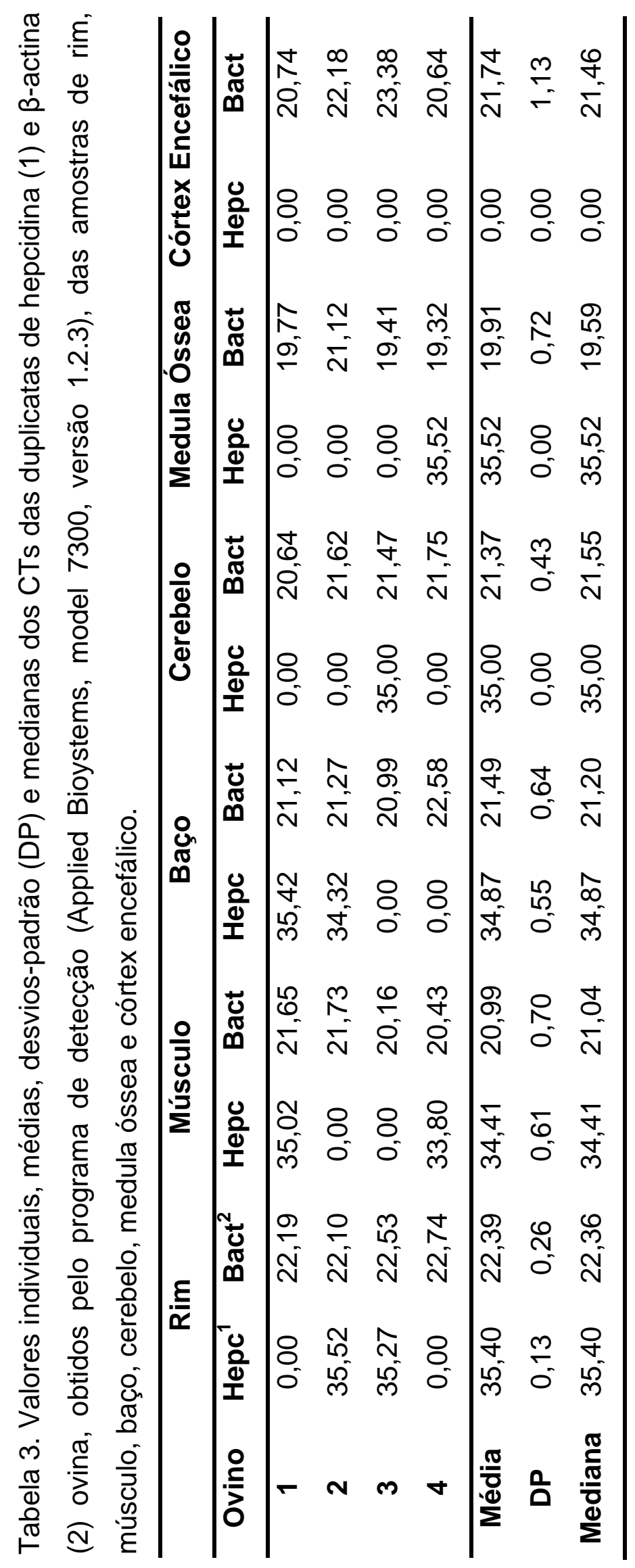


"RESEARCH IN VETERINARY SCIENCE" (NORMAS) 


\section{Normas para publicação no periódico "Research in Veterinary Science"}

The Official Journal of the Association for Veterinary Teaching and Research Work

\section{Guide for Authors}

Research in Veterinary Science publishes original contributions and review articles on research concerning the health and disease of animals, including studies in comparative medicine.

\section{Types of contribution}

1. Original research papers (Regular Papers)

2. Short Communications

3. Review articles

Original research papers should report the results of original research. The material should not have been previously published elsewhere, except in a preliminary form.

Short Communications should not exceed 1600 words and include no more than two tables or figures. They should have an abstract but no other divisions. Typescripts should be clearly marked Short Communication.

Review articles Review articles on veterinary topics are invited for publication. They should give an update on recent advances in a particular field and be targeted at research veterinarians who are not necessarily working in the same field. The length should not exceed 4000 words.

\section{Submission of manuscripts}

Submission to Research in Veterinary Science now proceeds online via Elsevier Editorial System - http://ees.elsevier.com/rvsc. Authors will be guided step-bystep through uploading files directly from their computers. Authors should select a set of classifications for their papers from a given list, as well as a category designation (Original Research Paper, Short Communication, and so on). 
Electronic PDF proofs will be automatically generated from uploaded files, and used for subsequent reviewing.

Authors should send queries concerning the submission process or journal procedures to AuthorSupport@elsevier.com. Authors can check the status of their manuscript within the review procedure using Elsevier Editorial System.

Authors submitting hard copy papers will be asked to resubmit using Elsevier Editorial System.

Submission of an article is understood to imply that the article is original and is not being considered for publication elsewhere. Submission also implies that all authors have approved the paper for release and are in agreement with its content. Upon acceptance of the article by the journal, the author(s) will be asked to transfer the copyright of the article to the Publisher. This transfer will ensure the widest possible dissemination of information.

All authors should have made substantial contributions to all of the following: (1) the conception and design of the study, or acquisition of data, or analysis and interpretation of data, (2) drafting the article or revising it critically for important intellectual content, (3) final approval of the version to be submitted.

\section{Acknowledgements}

All contributors who do not meet the criteria for authorship as defined above should be listed in an acknowledgements section. Examples of those who might be acknowledged include a person who provided purely technical help, writing assistance, or a department chair who provided only general support. Authors should disclose whether they had any writing assistance and identify the entity that paid for this assistance.

\section{Conflict of interest}

At the end of the text, under a subheading "Conflict of interest statement" all authors must disclose any financial and personal relationships with other people or organizations that could inappropriately influence (bias) their work. Examples of potential conflicts of interest include employment, consultancies, stock 
ownership, honoraria, paid expert testimony, patent applications/registrations, and grants or other funding.

\section{Role of the funding source}

All sources of funding should be declared as an acknowledgement at the end of the text. Authors should declare the role of study sponsors, if any, in the study design, in the collection, analysis and interpretation of data; in the writing of the manuscript; and in the decision to submit the manuscript for publication. If the study sponsors had no such involvement, the authors should so state.

Language Editing: Elsevier's Authors Home provides details of some companies who can provide English language and copyediting services to authors who need assistance before they submit their article or before it is accepted for publication. Authors should contact these services directly. For more information about language editing services, please email authorsupport@elsevier.com.

\section{Ethics}

Before papers describing animal studies are accepted for publication in Research in Veterinary Science, the authors must satisfy the editors that the work conformed to appropriate ethical standards. Whether or not a particular piece of work is accepted for publication will be decided by the editors whose decision will be final.

The authors should provide written assurances that: (i) The project underwent ethical review and was given approval by an institutional animal care and use committee or by appropriately qualified scientific and lay colleagues. (ii) The care and use of experimental animals complied with local animal welfare laws, guidelines and policies.

The editors expect authors to have adhered to the following general principles: (i) Alternative procedures that replace the use of animals should be used if possible. Where this is not possible, the animals used should be carefully selected to be the least sentient species possible and of an appropriate strain. 
(ii) The minimum number of animals should be used consistent with achieving the scientific objectives of the study. (iii) Pain and distress should be minimized by the use of humane endpoints, sedation, anaesthesia, analgesia and postoperative care. (iv) Access to veterinary care must be available at all times. (v) Investigators and personnel that care for and use animals must be trained and possess relevant expertise and training that should be updated regularly. (vi) If animals have to be killed, this should be done humanely according to local euthanasia regulations, such as the Home Office guidelines in the UK or guidelines of the American Veterinary Association Panel on Euthanasia.

\section{Title}

Papers should be headed with the full title, the initials and surnames of the authors, and the name and address of the institution where the work was carried out. The full telephone number, Fax number and e-mail address of the corresponding author should also be provided.

\section{Form of Papers}

a) Abstract (not more than 150 words), self-contained and embodying the main conclusions. It should note the relevance to veterinary science as well as the aims and objectives of the work. Sentences such as 'the results are discussed', which merely describe the paper, are not allowed.

b) Keywords. Please supply a list of up to six keywords that describe the paper.

c) Introduction.

d) Materials and methods employed.

e) Results, as concise as possible. Text, tables and figures illustrating the same data will rarely be permitted.

f) Discussion and conclusions.

g) Acknowledgements.

h) References.

i) Manuscripts should have numbered lines, with wide margins and double spacing, throughout, i.e. also for abstracts, footnotes and references. Every page of the manuscripts, including the tile page, references, tables, etc., should be numbered. However, in the text no reference should be made to 
page numbers; if necessary one may refer to sections. Avoid excessive usage of italics to emphasize part of the text.

Abbreviation and symbols: Authors are asked to explain each scientific abbreviation at it first occurrence in their papers; for example, complement fixations test (CFT). The policy of the journal with respect to units and symbols is that $\mathrm{SI}$ (System International) symbols should be used.

\section{Reference Format}

Only papers closely related to the author's work should be mentioned; exhaustive lists should be avoided. References should be cited in the text thus: Brown and Smith (1985), Jones (1987a), Jones (1987b), or Smith et al (1988). The list of references at the end of the paper should be given in alphabetical order and should appear in the form:- Torgerson, P.R., Budke, C.M., 2003 Echinococcosis - an international public health challenge. Research in Veterinary Science 74, 191-202. References to books and monographs should include: (1) author(s) or editor(s); (2) year of publication; (3) title; (4) edition; (5) place of publication and publisher; (6) beginning and final page numbers.

\section{Illustrations}

1. All illustrations (line drawings and photographs) should be submitted as separate files, preferably in TIFF or EPS format.

2. Illustrations should be numbered according to their sequence in the text. References should be made in the text to each illustration.

3. Illustrations should be designed with the format of the page of the journal in mind. Illustrations should be of such a size as to allow a reduction of $50 \%$.

4. Lettering should be big enough to allow a reduction of $50 \%$ without becoming illegible. Any lettering should be in English. Use the same kind of lettering throughout and follow the style of the journal.

5. If a scale should be given, use bar scales on all illustrations instead of numerical scales that must be changed with reduction.

6. Each illustration should have a caption. The captions to all illustrations should be typed on a separate sheet of the manuscript. 
7. Explanations should be given in the figure legend(s). Drawn text in the illustrations should be kept to a minimum.

8. Photographs are only acceptable if they have good contrast and intensity.

9. If you submit usable colour figures, Elsevier would ensure that these figures appeared free-of charge in colour in the electronic version of your accepted paper, regardless of whether or not these illustrations are reproduced in colour in the printed version. Colour illustrations can only be included in print if the additional cost of reproduction is contributed by the author: you would receive information regarding the costs from Elsevier after receipt of your accepted article.

Please note that because of technical complications which may arise by converting colour figures to 'grey scale' (for the printed version, should you not opt for colour in print), you should submit in addition usable black and white figures corresponding to all colour illustrations.

10. Advice on the preparation of illustrations can be found at the following URL: http://www.elsevier.com/artworkinstructions.

\section{Preparation of supplementary data}

Elsevier now accepts electronic supplementary material to support and enhance your scientific research. Supplementary files offer the author additional possibilities to publish supporting applications, movies, animation sequences, high-resolution images, background datasets, sound clips and more. Supplementary files supplied will be published online alongside the electronic version of your article in Elsevier web products, including Science Direct: http://www.sciencedirect.com. In order to ensure that your submitted material is directly usable, please ensure that data is provided in one of our recommended file formats. Authors should submit the material together with the article and supply a concise and descriptive caption for each file.

\section{Tables}

1. Authors should take notice of the limitations set by the size and lay-out of the journal. Large tables should be avoided. Reversing columns and rows will often reduce the dimensions of a table. 
2. If many data are to be presented, an attempt should be made to divide them over two or more tables.

3. Tables should be numbered according to their sequence in the text. The text should include references to all tables.

4. Each table should occupy a separate page of the manuscript. Tables should never be included in the text.

5. Each table should have a brief and self-explanatory title.

6. Column headings should be brief, but sufficiently explanatory. Standard abbreviations of units of measurement should be added between parentheses.

7. Vertical lines should not be used to separate columns. Leave some extra space between the columns instead.

8. Any explanation essential to the understanding of the table should be given as a footnote at the bottom of the table.

\section{Copyright}

If excerpts from other copyrighted works are included, the Author(s) must obtain written permission from the copyright owners and credit the source(s) in the article. Elsevier has preprinted forms for use by Authors in these cases: contact Elsevier's Rights Department, Oxford, UK: phone (+1) 2152393804 or $+44(0) 1865$ 843830, fax $\quad+44(0) 1865 \quad 853333$, e-mail healthpermissions@elsevier.com. Requests may also be completed online via the Elsevier homepage http://www.elsevier.com/permissions.

Material in unpublished letters and manuscripts is also protected and must not be published unless permission has been obtained.

\section{Authors Rights}

As an author you (or your employer or institution) may do the following:

- make copies (print or electronic) of the article for your own personal use, including for your own classroom teaching use

- make copies and distribute such copies (including through e-mail) of the article to research colleagues, for the personal use by such colleagues (but not commercially or systematically, e.g., via an e-mail list or list server) 
- post a pre-print version of the article on Internet websites including electronic pre-print servers, and to retain indefinitely such version on such servers or sites - post a revised personal version of the final text of the article (to reflect changes made in the peer review and editing process) on your personal or institutional website or server, with a link to the journal homepage (on elsevier.com)

- present the article at a meeting or conference and to distribute copies of the article to the delegates attending such a meeting

- for your employer, if the article is a 'work for hire', made within the scope of your employment, your employer may use all or part of the information in the article for other intra-company use (e.g., training)

- retain patent and trademark rights and rights to any processes or procedure described in the article

- include the article in full or in part in a thesis or dissertation (provided that this is not to be published commercially)

- use the article or any part thereof in a printed compilation of your works, such as collected writings or lecture notes (subsequent to publication of your article in the journal)

- prepare other derivative works, to extend the article into book-length form, or to otherwise reuse portions or excerpts in other works, with full acknowledgement of its original publication in the journal

\section{Funding body agreements and policies}

Elsevier has established agreements and developed policies to allow authors who publish in Elsevier journals to comply with potential manuscript archiving requirements as specified as conditions of their grant awards. To learn more about existing agreements and policies please visit http://www.elsevier.com/fundingbodies).

\section{Proofs}

One set of page proofs in PDF format will be sent by e-mail to the corresponding author (if we do not have an e-mail address then paper proofs will be sent by post). Elsevier now sends PDF proofs which can be annotated; for this you will need to download Adobe Reader version 7 available free from 
http://www.adobe.com/products/acrobat/readstep2.html. Instructions on how to annotate PDF files will accompany the proofs. The exact system requirements are given at the Adobe site: http://www.adobe.com/products/acrobat/acrrsystemreqs.html\#70win. If you do not wish to use the PDF annotations function, you may list the corrections (including replies to the Query Form) and return to Elsevier in an e-mail. Please list your corrections quoting line number. If, for any reason, this is not possible, then mark the corrections and any other comments (including replies to the Query Form) on a printout of your proof and return by fax, or scan the pages and e-mail, or by post. Please use this proof only for checking the typesetting, editing, completeness and correctness of the text, tables and figures. Significant changes to the article as accepted for publication will only be considered at this stage with permission from the Editor. We will do everything possible to get your article published quickly and accurately. Therefore, it is important to ensure that all of your corrections are sent back to us in one communication: please check carefully before replying, as inclusion of any subsequent corrections cannot be guaranteed. Proofreading is solely your responsibility.

\section{Author Enquiries}

For enquiries relating to the submission of articles (including electronic submission where available) please visit the journal's homepage at http://www.elsevier.com/locate/rvsc. This also provides the facility to track accepted articles and set up e-mail alerts to inform you of when an article's status has changed. Contact details for questions arising after acceptance of an article, especially those relating to proofs, are provided after registration of an article for publication.

\section{Off prints}

The corresponding author will, at no cost, be provided with a PDF file of the article via e-mail. The PDF file is a watermarked version of the published article and includes a cover sheet with the journal cover image and a disclaimer outlining the terms and conditions of use. 